\title{
Nanobiotechnology approaches for cardiovascular diseases: site-specific targeting of drugs and nanoparticles for atherothrombosis
}

\author{
Haikun Liu', Geoffrey Pietersz ${ }^{2,3,4}$, Karlheinz Peter ${ }^{2,4,5,6}$ and Xiaowei Wang ${ }^{1,2,4,5,6^{*}}$ (])
}

\begin{abstract}
Atherosclerosis and atherothrombosis, the major contributors to cardiovascular diseases (CVDs), represent the leading cause of death worldwide. Current pharmacological therapies have been associated with side effects or are insufficient at halting atherosclerotic progression effectively. Pioneering work harnessing the passive diffusion or endocytosis properties of nanoparticles and advanced biotechnologies in creating recombinant proteins for site-specific delivery have been utilized to overcome these limitations. Since CVDs are complex diseases, the most challenging aspect of developing site-specific therapies is the identification of an individual and unique antigenic epitope that is only expressed in lesions or diseased areas. This review focuses on the pathological mechanism of atherothrombosis and discusses the unique targets that are important during disease progression. We review recent advances in site-specific therapy using novel targeted drug-delivery and nanoparticle-carrier systems. Furthermore, we explore the limitations and future perspectives of site-specific therapy for CVDs.
\end{abstract}

Keywords: Antibodies, Atherosclerosis, Gene delivery, Nanoparticles, Targeted drug delivery, Thrombosis

\section{Graphical Abstract}

\section{Atherothrombosis}

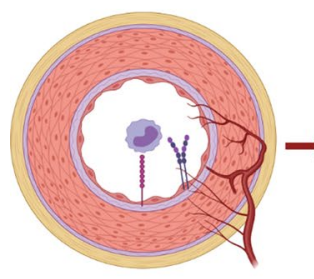

Endothelial dysfunction

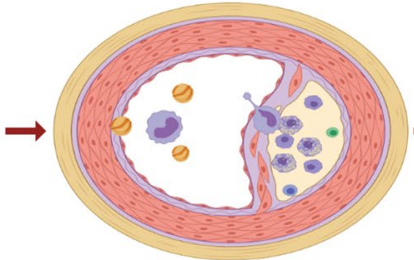

Monocytes recruitment \& foam cells

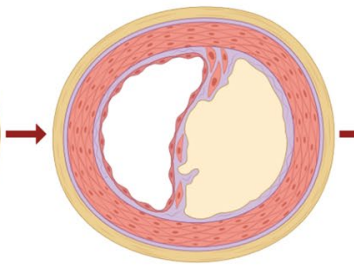

Plaque build up

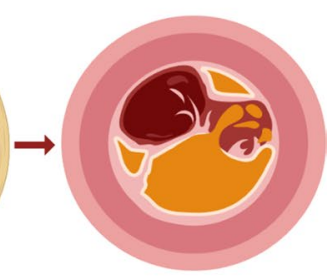

Plaque rupture \& thrombosis
*Correspondence: xiaowei.wang@baker.edu.au

${ }^{1}$ Molecular Imaging and Theranostics Laboratory, Baker Heart

and Diabetes Institute, 75 Commercial Road, Melbourne, VIC 3004, Australia

Full list of author information is available at the end of the article

\section{Introduction}

Cardiovascular diseases (CVD) are the leading cause of death globally, resulting in more than 17 million deaths per year [1]. The primary causes of the global CVD burden are ischemic heart disease and stroke (49\% and 35\% original author(s) and the source, provide a link to the Creative Commons licence, and indicate if changes were made. The images or other third party material in this article are included in the article's Creative Commons licence, unless indicated otherwise in a credit line to the material. If material is not included in the article's Creative Commons licence and your intended use is not permitted by statutory regulation or exceeds the permitted use, you will need to obtain permission directly from the copyright holder. To view a copy of this licence, visit http://creativecommons.org/licenses/by/4.0/. The Creative Commons Public Domain Dedication waiver (http://creativeco mmons.org/publicdomain/zero/1.0/) applies to the data made available in this article, unless otherwise stated in a credit line to the data. 
of the total burden, respectively) [2]. The main contributor to ischemic heart disease is atherosclerosis and its rupture, a process known as atherothrombosis [3]. Atherosclerosis of the major intracranial and carotid arteries also results in vessel alterations, ranging from minor wall thickening to hemodynamically substantial luminal stenosis, and is the leading cause of ischemic stroke globally [4]. Therefore, the prevention and treatment of atherosclerosis and atherothrombosis are essential to relieve the burdens of CVDs worldwide.

Atherosclerosis is a chronic inflammatory disease accompanied by lipid deposition, smooth muscle cell (SMC) proliferation, and plaque formation [5]. Unhealthy lifestyles such as poor diet quality, sedentariness, exposure to air pollution and noise, sleep deprivation, and psychosocial stress increase the risk of atherosclerosis [6]. The traditional applications of drugs are limited by insufficient effectiveness, poor distribution, and lack of selectivity [7].

Current pharmacological treatments focus on controlling the risk factors for atherosclerosis, such as glucoselowering, lipid-lowering, and anti-hypertensive drugs. However, the efficacy of these drugs in ameliorating or reversing atherosclerotic events has been limited and further studies are needed. The most effective medications for the prevention of MI and ischemic stroke are antiplatelet and anti-coagulation therapies, which have also been associated with bleeding complications [8]. Therefore, many groups have researched either targeted drug delivery or controlled carrier systems to overcome these limitations. Drawing on the success of targeted drug delivery in the cancer field, antibody-based therapy has been very successful over the last 15 years [9]. Similarly, CVD researchers have recently harnessed the targeting ability of antibodies for the treatment of atherosclerosis [10].

Using ligands that target specific biomarkers which are expressed and upregulated during the process of atherothrombosis allows for direct regulation of inflammation and delivery of drugs to specific disease locations. Another widely researched area for CVD therapy is nanoparticles (NPs) for the delivery of therapeutic compounds, due to their optimized physiochemical and biological properties [11]. NPs can be synthesized from organic and inorganic materials, including lipids, proteins, synthetic/natural polymers, and metals [12].

Advances in nanotechnology have led to the ability to design and generate NPs with optimal sizes (typically ranging between 1 and $100 \mathrm{~nm}$ ), shapes, and physiochemical properties [13]. The two main advantages of using NPs are: (1) protection of the drug cargo from degradation; and (2) prevention of off-target effects and protection of the in vivo environment from potentially harmful drugs by transporting and releasing drugs at the site of disease [14]. Both biomarker-specific targeting ligands and NPs have been used for imaging and treatment of atherothrombosis (Fig. 1) [3, 15]. This review introduces the pathological mechanism of atherothrombosis and discusses recent advances in site-specific therapy using novel targeted drug-delivery and NP-carrier systems, as well as a comparison between these two strategies.

\section{Pathogenesis of atherothrombosis}

Atherosclerosis is a chronic inflammatory disease characterized by lipid retention and vessel stiffening. Atherosclerosis is a complex pathological process characterized by structural abnormalities in the intima and media of arterial arteries, primarily caused by cholesterol accumulation, endothelial dysfunction, inflammatory cell infiltration, and vascular SMC migration (Fig. 2). High extracellular and intracellular lipid accumulation in advanced atherosclerotic plaques is implicated as the cause of the rupture, resulting in thrombosis and related clinical complications [16].

\section{The initiation of atherosclerosis}

Atherosclerosis usually begins in areas of disturbed flow, typically near vessel branches and vascular bends, leading

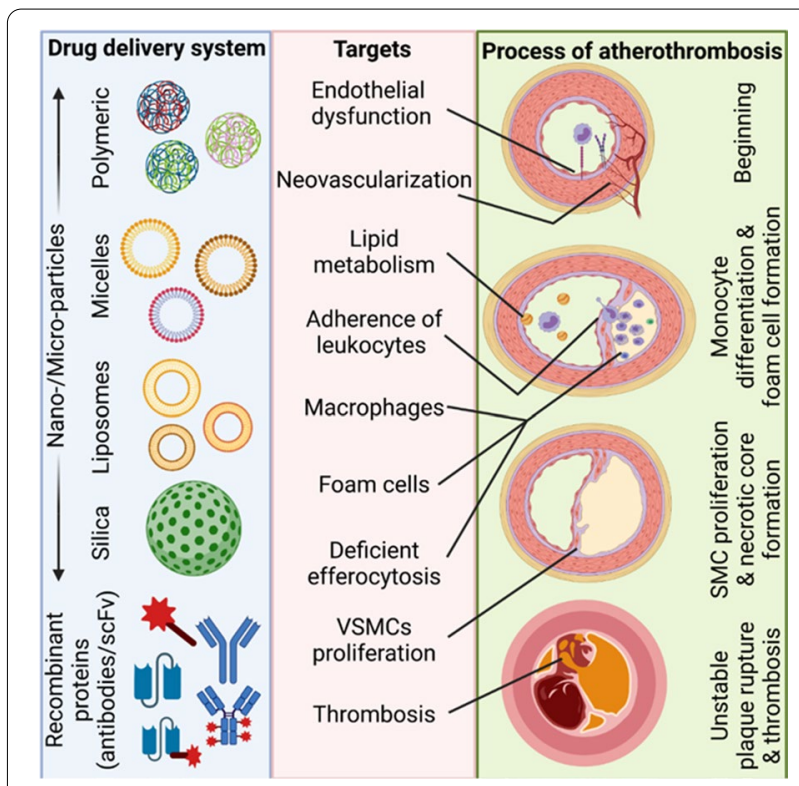

Fig. 1 Site-targeting drugs and NPs for different stages of atherothrombosis. NPs can be made from different biomaterials and various formats of antibodies can be used to target and disrupt the atherothrombosis stages of endothelial dysfunction, neovascularization, lipid metabolism, recruitment of leukocytes, phagocytosis of macrophages, and formation of foam cells, along with inefficient efferocytosis, vascular SMC proliferation, and thrombosis 


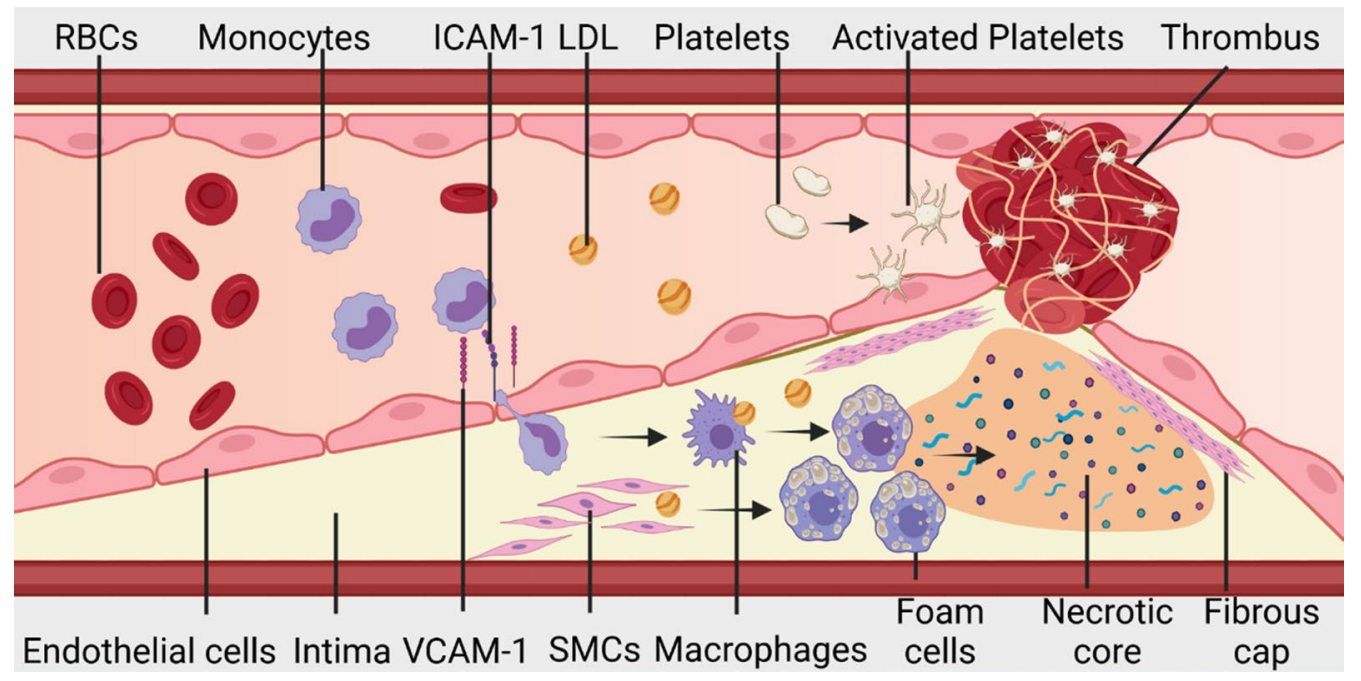

Fig. 2 The pathology of atherothrombosis. Endothelial dysfunction causes activated endothelial cells to express inflammatory molecules, including VCAM-1 and ICAM-1. Monocytes interact with these inflammatory cell surface receptors and accumulate in the intima of blood vessels. Monocytes differentiate into lipid-loaded macrophages: LDL is taken up by macrophages and vascular SMCs leading to the formation of foam cells and the development of plaques. Accumulating and apoptotic foam cells form a necrotic core. The growing necrotic core eventually disrupts the fibrous cap and the leaking content of the plaques induces thrombosis through a series of reactions such as activation of platelets and the initiation of coagulation

to low shear-stress recirculation, oscillation, or lateral flow [17]. Disturbed flow and its prolonged cyclic stretch on the endothelial cells have been associated with the secretion of pro-inflammatory chemokines, cytokines and high levels of reactive oxygen species (ROS) [18, 19]. These cytokines play a role in modulating endothelial cell permeability, thereby increasing the gaps between adjacent cells and compromising endothelial integrity [20]. The activation of endothelial cells leads to upregulation of a range of cell surface proteins, which in turn leads to the recruitment of leukocytes and monocytes which bind to the endothelial monolayer. Transmigration of monocytes, their infiltration of the intima and the dynamic accumulation of monocytes contribute massively towards lesion growth [20-23].

\section{Low-density lipoprotein accumulation and fatty streaks}

Low-density lipoprotein (LDL) cholesterol is one of the most important inducers of CVDs. Cholesterol is mainly derived via intestinal absorption [24]. The liver plays a central role in its metabolism, excretion and storage [25]. Increased local and systemic levels of LDL particles invade and accumulate in the endothelium, where they are subjected to oxidation to become oxidized low-density lipoprotein (OxLDL). This OxLDL results in early fatty-streak formation, as well as further inducing endothelial dysfunction and chemokine release [20]. Reports have shown that lowering LDL from a baseline of $92 \mathrm{mg} / \mathrm{dl}$ to $43 \mathrm{mg} / \mathrm{dl}$ resulted in a decrease in cardiovascular death by $17 \%$ and further lowering to $22 \mathrm{mg} / \mathrm{dl}$ resulted in a $20 \%$ risk reduction $[26,27]$.

\section{Leukocytes and monocyte differentiation}

The activation of endothelial cells leads to leukocyte recruitment by mediating monocytes rolling and promoting their adherence [28]. Depending on the cytokine signals received by monocytes, they can differentiate into dendritic cells or different phenotypes of macrophages, where classically activated (M1) macrophages has been shown to increase oxidative stress and produce proinflammatory cytokines [20, 29-31].

Macrophages derived from these circulating monocytes ingest the OxLDL, resulting in the formation of lipid-laden foam cells $[22,32]$. The dominant pathway for foam-cell formation is mediated by scavenger receptors [33] and other independent pathways also contribute to their retention [33-36]. The accumulation of lipid-laden foam cells and immune cells contributes to the expansion of the intima and disrupts the endothelial layer, thereby promoting atherosclerotic plaque formation.

\section{Proliferation of smooth muscle cells}

Vascular SMCs play multiple roles in the progression of atherosclerosis [21]. During atherosclerosis, vascular SMCs undergo phenotype switching from contractile to synthetic phenotypes, resulting in these vascular SMCs to acquire the properties of macrophages and later transforming into foam cells 
$[21,37]$. Furthermore, vascular SMCs also undergo cell proliferation, migration, and secretion of multiple extracellular matrix proteins and cytokines, all of which contribute to the formation of atherosclerotic plaques [37, 38]. Further down the track of atherosclerosis, vascular SMCs can also differentiate into osteoblast-like cells, promoting vascular calcification and aggravating plaque vulnerability [39]. It is also worth noting that vascular SMCs can play a protective role in atherosclerosis by constructing a fibrous cap which prevents rupture [40].

\section{Vessel remodeling and neovascularization}

As foam cells accumulate and the fibrous cap thickens in the lumen, the volume of the intima enlarges, resulting in vascular remodeling and restriction of blood flow. Such lesions are usually stable but contribute to clinical discomfort. Neovascularization of atherosclerotic vessels is mainly triggered by the hypoxic regions in the thickened plaques and has been associated with lesion vulnerability [41]. These newly formed microvessels commonly arise from the adventitial vasa vasorum, in areas with increased macrophage infiltration, enhanced lipid cores, and thick cap atheroma [42].

\section{Unstable plaque, rupture, and thrombosis}

Although luminal narrowing caused by an atherosclerotic plaque contributes to some clinical symptoms, most acute and severe clinical manifestations are triggered by atherothrombosis [43]. Three different morphological entities have been recognized as the etiology of coronary thrombosis: plaque erosion, calcified nodules, and plaque rupture. Plaque erosion usually occurs in lesions with high levels of proteoglycans and SMCs because their disruption of endothelial integrity exposes the underlying collagen, which becomes a nidus for thrombosis [44]. Calcified nodules occur primarily in older patients when disruption of calcified necrotic cores triggers thrombosis [45]. Rupture of the fibrous cap on an unstable or vulnerable atherosclerotic plaque leads to exposure of the necrotic core content such as tissue factors (TFs) to the flowing blood and they activate a coagulation cascade [46].

In summary, atherothrombosis is a complex disease which contributes to one in three deaths. Current pharmacological treatments have been associated with drug resistance and side effects $[8,47]$. Therefore, site-specific targeted drugs and the use of NPs as a controlled carrier system have been used to overcome the need for high systematic doses and the problem of bleeding complications.

\section{Site-specific drug delivery and nanoparticles}

The site-specific delivery of drugs has been widely researched in all medical fields. The use of NPs as drug-delivery strategies has been widely accepted in cancer therapy, with the first nanotherapeutic, Doxil, approved for clinical use in 1995 [48, 49]. Furthermore, NPs were clinically approved for drug therapy for acute myeloid leukemia in 2017 and for gene therapy for transthyretin-mediated amyloidosis in 2018 [48, 50]. The most recent clinical success in NP use is the two COVID-19 messengerRNA (mRNA)-based vaccines to combat severe acute respiratory syndrome coronavirus 2 (SARS-CoV-2) [51-55]. The successful use of nanomedicine in these medical areas has inspired many cardiovascular researchers to harness NPs' inherent properties such as their passive diffusion and endocytosis for in vitro and in vivo experiments. Passive accumulation can lead to unwanted off-target delivery; therefore, a range of conjugation techniques have been established to enable active targeting to specific biomarkers of CVDs or trigger drug release by responding to biological or technical stimuli. Since CVDs are complex diseases, the most difficult aspect of developing site-specific therapies is the ability to identify an individual and unique antigen that is only expressed in lesions or diseased areas. In the following sections, we will discuss some of these unique targets that are important or upregulated during the progression of atherosclerosis and atherothrombosis, as well as the research on the use of targeted drugs and NPs for drug delivery (Fig. 3).

\section{Strategies for targeting atherothrombosis Endothelial cells}

Vascular endothelial cells play several essential roles, including maintaining vascular homeostasis, regulation of vascular tension, proliferation of SMCs, and prevention of inflammation and thrombosis [56]. However, the activation of endothelial cells leads to the secretion of pro-inflammatory chemokines and cytokines, such as interleukin (IL)-8 and monocyte chemotactic protein-1 (MCP-1), and high levels of ROS [18, 19, 57, 58]. The activation also results in the upregulation of a range of cell surface proteins, including vascular cell adhesion molecule-1 (VCAM-1), intercellular cell adhesion molecule-1 (ICAM-1), P-selectin, and platelet endothelial cell adhesion molecule-1 (PECAM-1) (Fig. 4). Since endothelial dysfunction is the initial step in atherosclerosis, endothelial cells and their cell adhesion molecules have been intensively explored as crucial drug-delivery targets to prevent or slow the progress of atherosclerosis (Table 1) $[59,60]$. 


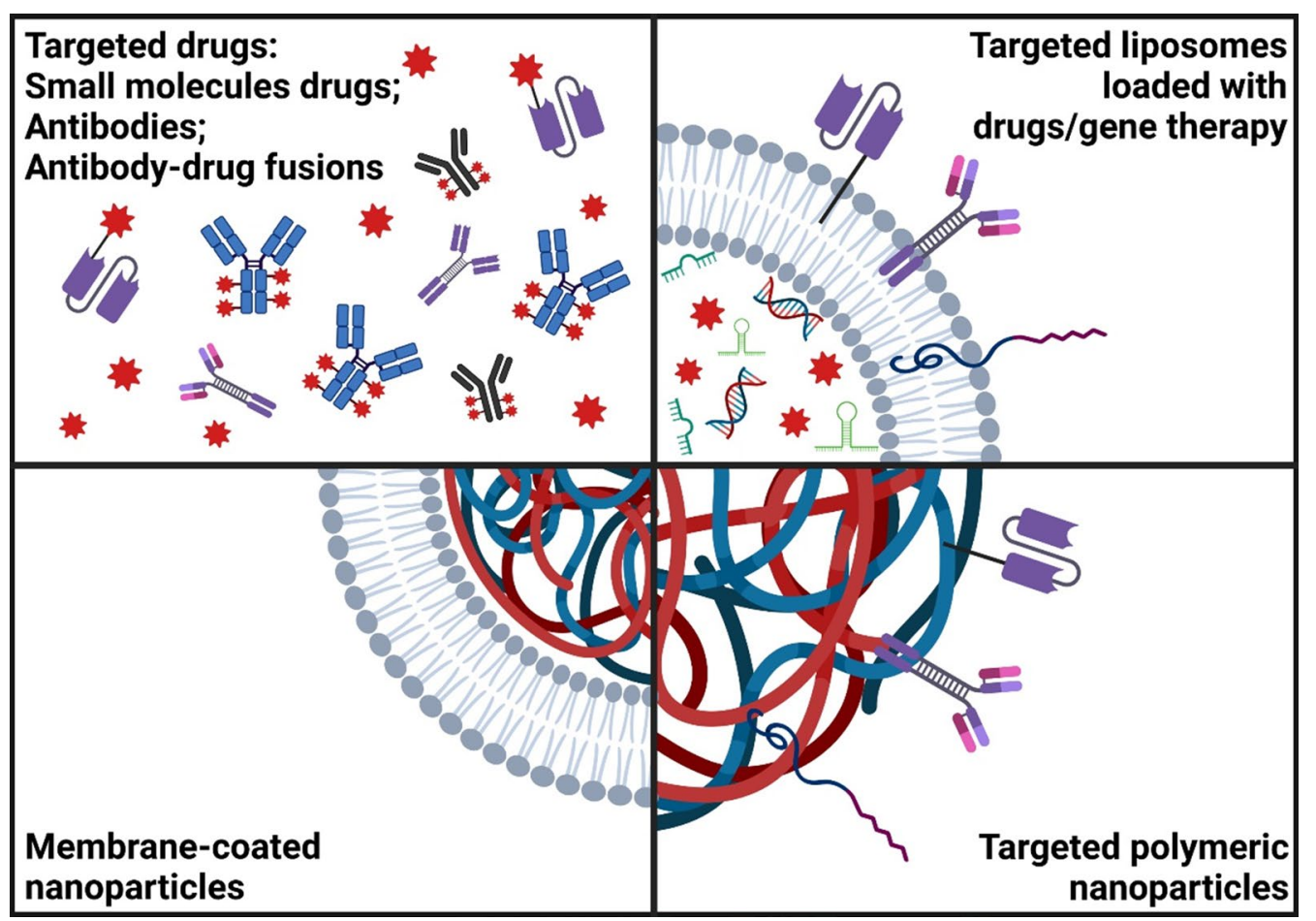

Fig. 3 Drug and nanoparticle targeting strategies. Small molecule drugs, scFv, IgG and recombinant antibody-drug fusion complexes; liposomes conjugated with binding molecules; polymeric nanoparticles conjugated with binding molecules; and membrane-coated nanoparticles

\section{Vascular cell adhesion molecule-1}

Of the different biomarkers upregulated on inflamed or dysfunctional endothelial cells, VCAM-1 results in leukocytes rolling/binding and is the most promising target $[18,61]$. Therefore, anti-VCAM-1 monoclonal antibodies (mAbs) have been investigated as a therapeutic agent for atherosclerosis. Park et al. developed mAbs against VCAM-1 (H6 and 7H) via phage display and found success in inhibiting atherosclerosis in vivo using a traditional apolipoprotein-E-deficient $\left(\mathrm{ApoE}^{-/-}\right)$ atherosclerosis murine model. The study also showed that anti-VCAM-1 mAbs reduced ROS generation and RhoA activation in endothelial cells and prevented lymphocyte transmigration by binding to the extracellular domains 1-2 of VCAM-1 [61]. Therefore, blocking of VCAM-1 can directly reduce leukocyte recruitment and inflammation.

In addition to direct anti-VCAM-1 blockage, groups have employed NPs and microparticles for targeted gene therapy [62, 63]. By altering gene expressions during CVDs, these studies have prevented the progression of atherosclerosis and rupture of aneurysms [62, 63]. Since regions with disturbed blood flow initiates the occurrence of atherosclerosis, studies have shown the upregulation of most flow-sensitive microRNA (miR)-712 [64, 65]. Increased levels of miR-712 directly downregulate

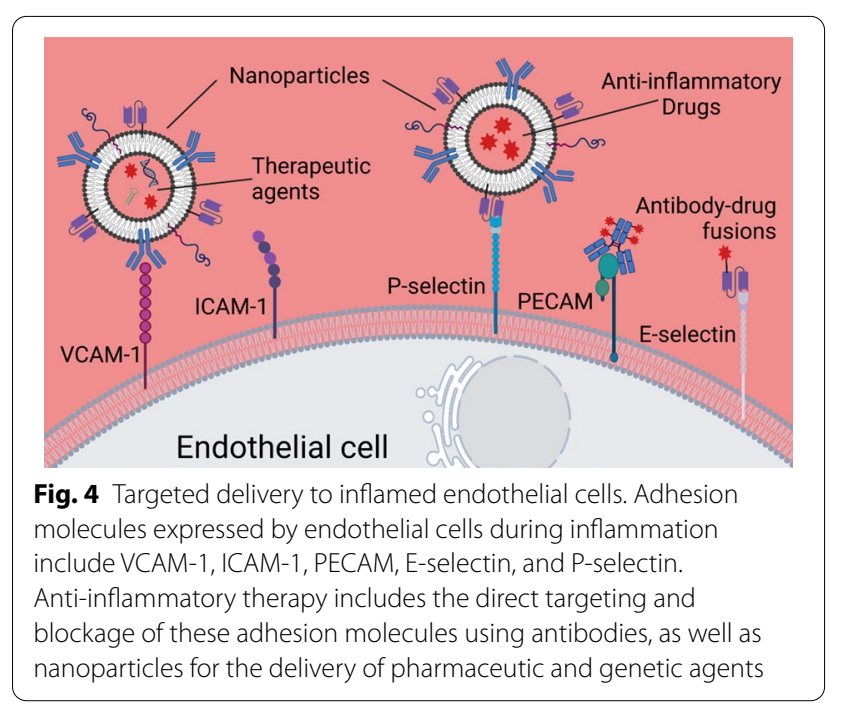

tissue inhibitors of metalloproteinase-3, which in turn contribute to the proliferation and migration of SMCs [65-67]. Kheirolomoom et al. designed a VCAM-1targeting cationic liposome to deliver anti-miR-712 to endothelial cells using a peptide sequence of VHPKQHR (VHPK), which is a VCAM-1-internalizing sequence [62]. This study demonstrated the selective uptake of the 
Table 1 Antibodies and NPs targeting endothelial cells

\begin{tabular}{|c|c|c|c|c|}
\hline Targeting approach & Delivered drugs & Models & Effect & Refs. \\
\hline PLGA NP + GPIb fragment & Dexamethasone & $\begin{array}{l}\text { In vitro HAECs and } \\
\text { ex vivo carotid artery of mice }\end{array}$ & $\begin{array}{l}\text { GPIb-conjugated NPs had five-fold } \\
\text { greater absorption by HAECs }\end{array}$ & {$[81]$} \\
\hline DOPE-liposome & CD39 mRNA & In vitro A549 cell & $\begin{array}{l}\text { Induced a significant change in } \\
\text { CD39 expression }\end{array}$ & {$[84]$} \\
\hline Anti-VCAM-1 mAbs & Anti-VCAM-1 mAbs & $\mathrm{ApoE}^{-/-}$on HFD (mice) & Inhibited vascular inflammation & {$[61]$} \\
\hline Cationic liposome + VHPK & miRNA-712 & Carotid ligation (mice) & Prevented atheroma development & {$[62]$} \\
\hline MB + anti-VCAM-1 scFv & miRNA-126 & Ang $\|$ induced AAA (mice) & $\begin{array}{l}\text { Changed vessel diameter in AAA } \\
\text { murine model }\end{array}$ & {$[63]$} \\
\hline $\begin{array}{l}\text { Liposomes + E-selectin-binding } \\
\text { peptide }\end{array}$ & $\begin{array}{l}\text { Atorvastatin calcium \& Curcuma } \\
\text { longa }\end{array}$ & $\mathrm{ApoE}^{-/-}$on HFD (mice) & $\begin{array}{l}\text { Inhibited E-selectin and ICAM-1 } \\
\text { expression, lowered plasma lipid, } \\
\text { prevented foam-cell formation and } \\
\text { secretion of inflammatory factors }\end{array}$ & {$[72]$} \\
\hline $\begin{array}{l}\text { Copolymer + E-selectin-binding } \\
\text { peptide }\end{array}$ & Dexamethasone & $\mathrm{ApoE}^{-/-}$on HFD (mice) & $\begin{array}{l}\text { Regressed and stabilized atheroscle- } \\
\text { rotic plaques }\end{array}$ & {$[73]$} \\
\hline $\begin{array}{l}\text { Microparticles + E-selectin-binding } \\
\text { thioaptamer }\end{array}$ & $\operatorname{miR} 145 a \&$ miR181b & $\mathrm{ApoE}^{-/-}$on HFD (mice) & $\begin{array}{l}\text { Decreased plaque size and mac- } \\
\text { rophage infiltration in the aortic } \\
\text { root }\end{array}$ & {$[74]$} \\
\hline $\begin{array}{l}\text { Lipid nanoemulsions conjugated to } \\
\text { E-selectin-binding peptide }\end{array}$ & Dexamethasone & C57BL/6 (mice) & $\begin{array}{l}\text { Significantly decreased expression } \\
\text { of pro-inflammatory markers and } \\
\text { endothelium activation, as well as } \\
\text { monocyte infiltration }\end{array}$ & {$[79]$} \\
\hline $\begin{array}{l}\text { P-selectin-targeted cationic } \\
\text { PEGylated liposome }\end{array}$ & RAGE-short hairpin (sh) RNA & ApoE ${ }^{-/-}$on HFD (mice) & $\begin{array}{l}\text { Inhibited leukocytes recruitment } \\
\text { and subsequent atherosclerosis }\end{array}$ & {$[80]$} \\
\hline Peptide analogue IELLQAR & Selectin inhibition & $\mathrm{ApoE}^{-/-}$on HFD (mice) & $\begin{array}{l}\text { Inhibited selectin binding to mono- } \\
\text { cytes and subsequent atheroscle- } \\
\text { rosis }\end{array}$ & {$[75]$} \\
\hline Oligopeptide-modified pBAE NP & SiRNA & C57BL/6 (mice) & $\begin{array}{l}\text { Tissue-driven targeting with high } \\
\text { affinity to the artery endothelium, } \\
\text { lung, and kidney }\end{array}$ & [87] \\
\hline
\end{tabular}

particles into the endothelium and the inhibition of atherosclerosis in vivo using a traditional $\mathrm{ApoE}^{-/-}$murine atherosclerosis model [62].It is worth noting that antimiR-712 was only internalized by the surface endothelial cells and was not further transported into the vessel wall, which might indicate that the NPs are too large to travel through the endothelial layer.

Abdominal aortic aneurysm (AAA), which has a frightful mortality rate of up to $90 \%$, if undetected and left untreated [2,68]. AAA's pathological characteristics exhibit close similarities to atherosclerosis, where strong inflammatory and thrombotic processes are driving forces of both diseases [69]. Wang et al. designed theranostic particles for concomitant diagnosis and therapy [63]. The group used a single-chain variable fragment antibody ( $\mathrm{scFv})$ that targets VCAM-1 to direct their microbubbles (MBs) (the ultrasound contrast agent) toward the inflamed endothelial cells on the vessels in an angiotensin II-induced AAA murine model [63]. The authors then coated the VCAM-1-targeted MBs with miR-126-5p, which has been shown to inhibit VCAM-1 expression and atherosclerosis [70]. To prevent off-target effects, the group also applied ultrasound pressure to the abdominal artery to burst the MBs and deliver the miR-126 into the endothelial layer [63]. After 4 weeks of dual-targeted treatment, the vessel diameter of the AAA murine model remained unaffected by angiotensin II induction, whereas there was an increase in vessel diameter in the control groups [63]. There were also massive areas of plaque buildup and ruptured aneurysms in control groups which were not observed with the dual-targeted treatment (Fig. 5) [63]. Since MBs have already been approved by the US Food and Drug Administration (FDA), the clinical translation of this technique may be substantially faster than with unapproved, newly generated particles. The development of AAA, including the intraluminal thrombosis is very similar to the pathogeneses of atherosclerosis and atherothrombosis. These diseases share multiple common mechanisms, such as the destabilization of the vessel wall and endothelial dysfunction $[69,71]$. Wang et al's dual targeted approach employing theranostic particles for AAA may also initiate the development of theranostic strategies for atherothrombosis. 

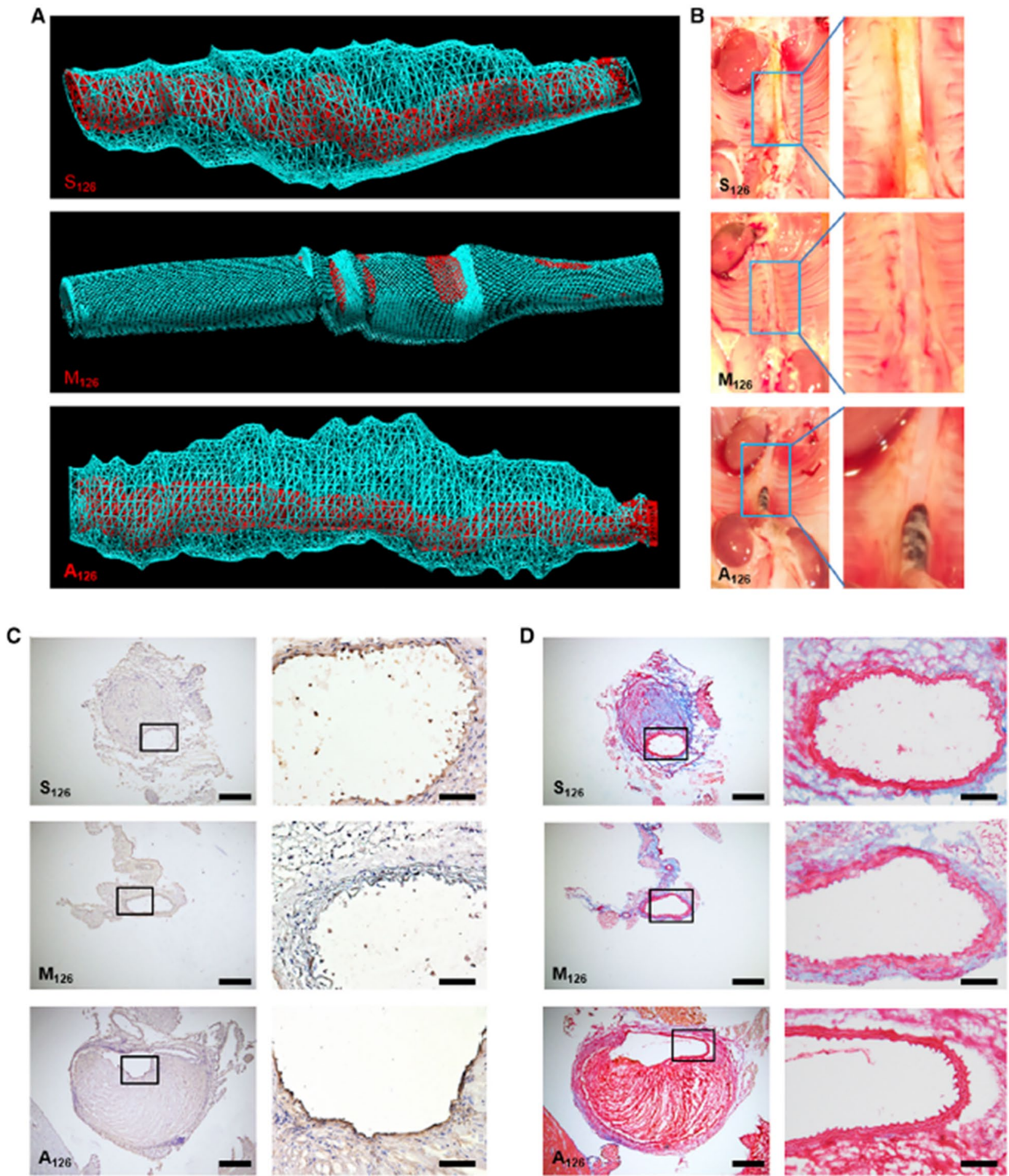

Fig. 5 Representative images of 3D ultrasound reconstructions of abdominal aorta, photographs of vessel isolations, immunohistochemistry, and Martius Scarlet Blue demonstrating profound effect of VCAM-1-targeted miR-carrying microbubbles. A 3D ultrasound reconstruction of abdominal aorta shows vessel lumen (in red), as well as massive areas of plaque build-up and aneurysm (in blue), from animals treated with Targ ${ }^{\mathrm{MB}}{ }_{-} \mathrm{A}_{126} \mathrm{Or}$ $\operatorname{Targ}^{\mathrm{MB}}{ }_{-} \mathrm{S}_{126}$ but not in animals treated with Targ ${ }^{\mathrm{MB}_{-} \mathrm{M}_{126}}$ B Vessel isolation shows clean abdominal aorta in mice treated with Targ ${ }_{-\mathrm{M}_{126}}$ but $^{\mathrm{MB}}$ plaque build-up and aneurysms in mice given Targ ${ }^{\mathrm{MB}}{ }_{-} \mathrm{S}_{126}$ or $\operatorname{Targ}^{\mathrm{MB}}{ }_{-} \mathrm{A}_{126}$. C Immunohistochemistry confirmed a decrease in VCAM-1 expression for Targ ${ }^{\mathrm{MB}}-\mathrm{M}_{126}$ treated animals as compared to those treated with $\operatorname{Targ}^{\mathrm{MB}}{ }_{-} \mathrm{A}_{126}$ or $\operatorname{Targ}^{\mathrm{MB}}{ }_{-} \mathrm{S}_{126}$. D Martius Scarlet Blue showed plaque build-up and aneurysms in abdominal arteries of $\operatorname{Targ}^{\mathrm{MB}}-\mathrm{A}_{126}$ or Targ $^{\mathrm{MB}_{-} \mathrm{S}_{126}}$ treated animals, whereas very little plaque build-up was observed in Targ ${ }^{\mathrm{MB}}-\mathrm{M}_{126}$ treated mice [63] 


\section{Endothelial-leukocyte cell adhesion molecule (E-selectin)}

E-selectin is expressed on inflamed endothelial cells upon their activation via cytokines. Using liposomes conjugated with an E-selectin-binding peptide, Li et al. performed targeted co-delivery of hypolipidemic and anti-oxidation drugs in vivo and observed atherosclerosis inhibition in a traditional $\mathrm{ApoE}^{-1-}$ murine atherosclerosis model [72]. The authors used atorvastatin calcium to reduce plasma lipid and Curcuma longa, which has anti-oxidation and anti-inflammatory properties [72]. Their therapeutic liposomes inhibited the expression of E-selectin and ICAM-1 in vitro and prevented foamcell formation in vivo. The levels of plasma lipid and expression of inflammatory factors (IL- 6 and MCP-1) were also lower in treated mice [72]. Although the study authors also mentioned that their targeted therapy might reduce the current side effects of atorvastatin calcium, such as central nervous system complaints, CoQ10-lowering effects, and diabetic mellitus, these data were not presented.

Another study by Tsoref et al. employed an E-selectinbinding peptide to deliver an anti-inflammatory drug (dexamethasone) by packaging it into polymer-based NPs [73]. These targeted drug-loaded NPs resulted in the regression and stabilization of atherosclerotic plaques, as well as the prevention of left ventricular remodeling in $\mathrm{ApoE}^{-/-}$mice [73]. Using the E-selectin thioaptamer conjugated on nanoporous silicon microparticles to deliver atheroprotective miR-145a and miR181b, Ma et al. successfully decreased plaque size and macrophage infiltration in the aortic root of $\mathrm{ApoE}^{-1-}$ mice [74]. The study also showed increased numbers of SMCs and collagen content in plaque areas, resulting in a reduction in atherosclerosis in vivo [74]. Overall, these studies indicated that E-selectin and VCAM-1 are ideal biomarkers for targeted drug and gene delivery towards inflamed endothelial cells.

\section{P-selectin}

P-selectin is expressed on damaged endothelium during inflammation. A recent study by Ye et al. investigated the use of a peptide analogue that inhibits P-selectin binding and demonstrated a reduction in the formation of atherosclerotic plaques and infiltration of monocytes/ macrophages in the arterial wall of $\mathrm{ApoE}^{-1-}$ mice [75]. Other groups have used the sialyl LewisX (sLeX) carbohydrate to target P-selectin and demonstrated reduced monocyte adhesion and endothelium injury [76]. Using a combination of sLeX and a P-selectin-inhibiting antibody, Ikeda et al. showed that this therapy prevented the adherence of platelets to leukocytes at the stenotic sites on the damaged endothelium in a canine model [77]. Using liposomes conjugated with the P-selectin glycoprotein ligand 1, these P-selectin-targeting particles resulted in greater than sevenfold binding affinity toward activated epithelial cells in vitro [78]. Nanoemulsions loaded with dexamethasone and conjugated to P-selectin-binding peptides demonstrated accumulation in the lungs of mice in a lipopolysaccharide-induced systemic inflammation model [79]. These targeted particles significantly decreased the expression of pro-inflammatory markers and endothelium activation, as well as monocyte infiltration, thereby reducing the inflammation in the lungs [79]. A recent study by Mocanu et al. demonstrated that P-selectin-targeted liposomes for transfection of short hairpin RNA, encoded for RAGE, resulted in the downregulation of RAGE expression and the prevention of atherosclerotic plaques in $\mathrm{ApoE}^{-/}$mice [80]. Expression of P-selectins on endothelial cells also triggers binding by the platelet glycoprotein Ib-alpha (GPIb $\alpha$ ). Therefore, Kona et al. developed poly(lactic-co-glycolic acid) (PLGA) NPs conjugated with glycocalicin, which is the external soluble cleaved fragment of platelet GPIb $\alpha$, to deliver dexamethasone [81]. These targeted biodegradable NPs had an increased uptake by human aortic endothelial cells in vitro and in the carotid artery of mice ex vivo [81]. However, since P-selectins are upregulated on both endothelial cells and activated platelets, there is a need for further in vivo studies to determine their biodistribution and in vivo therapeutic effect, as well as to investigate any possible complications.

\section{Novel genetic therapy approaches for endothelial dysfunction}

Many groups have investigated gene therapy targeting endothelial dysfunction in recent years due to its involvement with inflammation. Novel NPs have been created to transport and protect nucleic acids during their delivery. The delivery of mRNA is a challenge because it can be easily degraded by nucleases and is intrinsically unstable [82]. Therefore, Michel et al. developed a nanoliposomal system using $3 \beta-\left[\mathrm{N}-\left(\mathrm{N}, \mathrm{N}^{\prime}\right.\right.$-dimethylaminoethane) carbamoyl] (DC-cholesterol)/dioleoyl-phosphatidyl-ethanolamine (DOPE) nanoliposomes to protect the mRNA and facilitate their delivery into the cells, and this provided a long-lasting therapeutic effect in vitro [83]. These nanoliposomes have also been reported to be highly hemocompatible and biocompatible in vitro [83]. CD39, a nucleoside triphosphate diphosphohydrolase (NTPDase), is expressed on endothelial cells and has anti-inflammatory and anti-thrombotic effects. Using CD39 coding mRNA, Abraham et al. demonstrated that their nanoliposomes exhibited a high degree of mRNA encapsulation and high efficiency of transfection in vitro [84]. CD39 hydrolyzes both the pro-inflammatory adenosine triphosphate (ATP) and pro-thrombotic adenosine diphosphate 
(ADP) to the anti-inflammatory and anti-thrombotic adenosine monophosphate (AMP). Furthermore, mice lacking CD39 always exhibit a pro-thrombotic and proinflammatory response from endothelial cells, with increased production of ICAM-1 and VCAM-1, as well as the release of TNF- $\alpha$ and $\mathrm{VWF}$, and decreased antiinflammatory mediators [85]. However, these transgenic mice also exhibited impaired platelet function and an increase in bleeding time [86]. Therefore, this successful in vitro study of CD39 mRNA requires in vivo investigation to determine its suitability as a potential therapy.

To overcome the interaction of NPs with serum lipoproteins and their passive accumulation in the liver, Dosta et al. developed a series of oligopeptide-modified poly-beta-amino ester (pBAE) NPs to deliver small interfering RNA (siRNA) against ICAM-2 in vivo [87]. The group chose pBAE because it is a biodegradable and biocompatible polymer that can penetrate cell membranes easily [88]. While the final choice of the group named C6-KH was selected for in vivo studies, all 7 pBAEs bound to endothelial cells, vascular SMCs, and THP-1 monocytes to some degree [87]. Ex vivo studies using the abdominal aortas of mice showed binding of these NPs to vessel walls, while in vivo biodistribution studies showed a significant reduction in ICAM-2 levels in the lungs and the kidneys, but a slight increase in the spleen and no difference in the thymus, liver, or heart [87]. While the study did not explain why these NPs would accumulate and downregulate ICAM-2 expression in the lungs and kidneys of the healthy animals, it may be due to nonspecific uptake of NPs by the reticuloendothelial system. Thus, in vivo studies need to be completed to determine their specificity to avoid off-target effects, and successful application as a therapeutic strategy. Overall, NPs protect the nucleic acids from degradation in vivo and the functionalization of these NPs to target specific biomarkers will result in site-specific therapy and minimize the offtarget effects.

\section{Leukocytes}

Adhesion molecules, particularly leukocyte $\beta_{2}$-integrins, mediate the recruitment of leukocytes to the inflamed endothelial layer [89]. The macrophage-1 (Mac-1) antigen $\left(\alpha_{M} \beta_{2}, C D 11 b / C D 18\right.$, complement receptor 3$)$ is a $\beta_{2}$-integrin family member that is abundantly expressed on monocytes and neutrophils [90]. Its ectodomains can be stimulated to an active conformation by cellular activation, allowing it to interact with various ligands such as fibrinogen, C3bi, ICAM-1, and heparin [91]. In a recent study, a designed ankyrin repeat protein (DARPin) that specifically targets the $\beta_{2}$-integrin Mac-1 successfully prevented Mac-1 activation [92]. Siegel et al. also showed that the Mac-1-specific DARPin impeded vascular inflammation via significantly reduced monocyte binding with ICAM-1 and demonstrated advantageous crossreactivity between human and mice monocytes and neutrophils [92]. This new compound also effectively prevented leukocytes from migrating to the peritoneal lavage from blood, inhibited monocyte-cardiomyocyte interactions, and improved myocarditis and cardiac ischemic/ reperfusion (I/R) injury in vivo [92]. This DARPin may be a novel tool that inhibits inflammation by preventing interaction between leukocyte $\beta_{2}$-integrins and adhesion molecules, as well as other downstream therapies. The use of DAPRins has several benefits, 1) their small size allows better tissue penetration and high potency at low concentrations, 2) microbial expression allows for large scale production, and 3) they are thermodynamically stable.

While the inhibition of leukocytes adhesion has been proven successful in preventing atherosclerosis and endocytosis of phagocytes, it can also be harnessed to transport NPs to inflamed lesions and plaques through cellular recruitment and infiltration [93]. To reduce ROS levels, Wang et al. created NPs using cyclic polysaccharide $\beta$-cyclodextrin, which removes cholesterol, and phenylboronic acid pinacol ester, which is a catalase mimetic chemical to remove hydrogen peroxide effectively [107]. Using flow cytometry, the authors demonstrated that triple-drug-loaded NPs were taken up by lymphocytes, neutrophils, and Ly-6C $C^{\text {low }}$ and Ly- $6 C^{\text {high }}$ monocytes, as well as macrophages and SMCs in vivo [94]. Furthermore, in vivo studies using traditional $\mathrm{ApoE}^{-1-}$ mice after treatment with triple-drug-loaded NPs showed stabilized plaques, along with fewer macrophages and lower levels of ROS, TNF- $\alpha$, IL- $1 \beta$, and MMP-9 as compared with mice treated with control drugs [94]. The therapeutic benefits mainly resulted from reduced systemic and local oxidative stress and inflammation, as well as decreased inflammatory cell infiltration in atherosclerotic plaques [94]. While the use of these leukocyte markers have been successful in reducing inflammation, these therapies have also been shown to be beneficial in other diseases, such as sepsis $[92,95]$. Therefore, more in vivo studies need to be conducted to ensure that the targeting and direct inhibition of leukocytes do not affect other immunological responses in the body.

\section{Macrophages}

Phagocytosis of OxLDL makes macrophages one of the major contributors to plaque development; this phagocytic property also allows them to engulf non-targeted NPs more efficiently than monocytes [94, 96]. Therefore, many researchers have exploited the passive accumulation of drug-loaded NPs in macrophages as an approach to disrupting atherosclerosis (Table 2). 
Table 2 NPs targeting macrophages

\begin{tabular}{|c|c|c|c|c|}
\hline Targeting approach & Delivered drugs & Models & Effect & Refs. \\
\hline Amphiphilic macromolecule (AM) & & In vitro SMCs & $\begin{array}{l}\text { Prevented LDL internalization in } \\
\text { SMCs and reduced MSR1 and CD36 } \\
\text { expression }\end{array}$ & {$[108]$} \\
\hline $\mathrm{AM}(1 \mathrm{cM})$ & Ferulic acid & $\begin{array}{l}\text { In vitro human monocyte- derived } \\
\text { macrophages }\end{array}$ & $\begin{array}{l}\text { Reduced uptake of oxLDL and ROS } \\
\text { level }\end{array}$ & {$[103]$} \\
\hline Scorpion-like AM & Lithocholic acid & $\begin{array}{l}\text { In vitro human monocyte- derived } \\
\text { macrophages }\end{array}$ & $\begin{array}{l}\text { Lowered oxLDL uptake by mac- } \\
\text { rophages }\end{array}$ & {$[107]$} \\
\hline PLA-PEG NP & Rosiglitazone (RSG) & In vitro RAW264.7 macrophages & Significantly inhibited IL-10 expression & {$[121]$} \\
\hline rHDL NP & Statin & $\mathrm{ApoE}^{-/-}$on HFD (mice) & $\begin{array}{l}\text { Accumulated in macrophages and } \\
\text { decreased inflammation and lower } \\
\text { inflammatory factors }\end{array}$ & {$[96,100]$} \\
\hline AM & GW3965 & HFD (rats) & $\begin{array}{l}\text { Lowered intimal levels of accumulated } \\
\text { cholesterol, inhibited macrophage } \\
\text { retention }\end{array}$ & {$[105]$} \\
\hline $\begin{array}{l}\left.\text { Sugar-based AM (M }{ }_{12} P E G\right) \text { against } \\
\text { MSR1 \& CD36 SR }\end{array}$ & & ApoE $^{-/-}$mice on Harlan Teklad diet & $\begin{array}{l}\text { Reduced artery occlusion, inhibited } \\
\text { uptake of oxLDL, downregulated } \\
\text { expression of SRs }\end{array}$ & {$[106]$} \\
\hline Mannose-functionalized NPs & LXR ligand & $\mathrm{LDLR}^{-/-}$on HFD (mice) & $\begin{array}{l}\text { Reduction of lesion area in atheroscle- } \\
\text { rotic plaques }\end{array}$ & {$[138]$} \\
\hline \multirow[t]{3}{*}{ Hyaluronan NPs } & & $\mathrm{ApoE}^{-/-}$on HFD (mice) & $\begin{array}{l}\text { Lowered number of immune cells in } \\
\text { plaques }\end{array}$ & {$[111]$} \\
\hline & LOX-1 SiRNA & ApoE ${ }^{-/-}$on HFD (mice) & $\begin{array}{l}\text { Reduced plaque area and lipid } \\
\text { content }\end{array}$ & {$[113]$} \\
\hline & Simvastatin & $\mathrm{ApoE}^{-/-}$on HFD (mice) & Significantly reduced plaque size & {$[114]$} \\
\hline $\begin{array}{l}\text { Cationic peptide containing } \mathrm{pH}- \\
\text { sensing residues }(\mathrm{p} 5 \mathrm{RHH})\end{array}$ & JNK2 siRNA & $\mathrm{ApoE}^{-/-}$on HFD (mice) & $\begin{array}{l}\text { Decreased thrombotic risk, restored } \\
\text { endothelial barrier integrity, reduced } \\
\text { plaque necrosis, and depleted plaque- } \\
\text { macrophage content }\end{array}$ & {$[115]$} \\
\hline
\end{tabular}

\section{Reconstituted high-density-lipoprotein-based drug-delivery systems}

Reconstituted high-density lipoproteins (rHDLs) are atheroprotective because they interact with ATP-binding cassette transporters (ABCA1, ABCG1) and the scavenger receptor $\mathrm{B} 1$ to remove cholesterol from lipid-laden macrophages [97-99]. Using rHDL as a basis for PLGA NPs, Sanchez-Gaytan et al. demonstrated their accumulation in the plaques of $\mathrm{ApoE}^{-/-}$atherosclerotic mice, as well as their co-localization with macrophages [100]. By combining rHDL NPs with a lipid-lowering drug, statin [101], Duivenvoorden et al. demonstrated their potential in reducing plaque inflammation and inhibiting plaque progression in vivo [96]. The authors observed that intravenously delivered statin-loaded rHDL NPs increased the bioavailability and infiltration of statin in atherosclerotic plaques [96]. The mRNA expression levels of monocyte-recruitment genes (MCP-1, CCL-3, ICAM-1, VCAM-1, CCL-15, and CXCL-12), as well as pro-inflammatory genes (TNF-a, IL-1b, IL-1a, and SPP$1)$, were significantly lower in the treated mice as compared to the control mice treated with statin orally [96]. While more in vivo studies are needed to further evaluate the efficacy and biodistribution of these NPs, it is worth noting that HDL is a natural atheroprotective lipoprotein and is currently in Phase 3 clinical trials (ClinicalTrials. gov - NCT03473223) [102]. Therefore, the use of HDL as a building block for NPs and its combination with lipidlowering drugs may provide an attractive therapeutic approach for atherosclerosis.

\section{Amphiphilic macromolecule-based drug-delivery systems}

The Moghe group has developed a series of amphiphilic macromolecules (AMs) to deliver a range of therapeutics to macrophages using amphiphilic polymers containing a carboxylic acid group that binds scavenger receptors of macrophages, thereby inhibiting the uptake of oxLDL [103-107]. Using sugar-based AMs that bind scavenger receptors of macrophages, Chan et al. discovered that they could prevent up to $90 \%$ of LDL internalization in SMCs and inhibit up to $48 \%$ of macrophage scavenger receptor 1 (MSR1) expression and 33\% of CD36 expression in an in vitro study [108].

Polyphenol compounds, such as vitamin E and ferulic acid, have been utilized in therapies for atherosclerosis because of their hypolipidemic, antiinflammatory, and anti-oxidative effects [103, 109]. However, a high concentration of antioxidants plays a 
reverse role, causing oxidative stress, and may result in exacerbation of foam-cell formation in lesions [110]. Therefore, a system that directs the delivery of antioxidants to atherosclerosis sites and provides slow release is preferred. Chmielowski et al. incorporated ferulic acid into these AMs to counteract oxLDL uptake and regulate ROS generation, limiting macrophage foamcell formation [103]. Moretti et al. incorporated lithocholic acid, an agonist against the G-protein coupled receptor 19 that is known to reduce inflammation, and demonstrated a slight downregulation of scavenger receptors and pro-inflammatory cytokine (IL-1 $\beta$, IL-8, and IL-10) expression [107]. However, both studies were in vitro; therefore, further studies need to be conducted to determine their efficacy in vivo. Using sugar-based AMs, Lewis et al. demonstrated that they accumulated at atherosclerotic lesions, where they reduced plaque formation and lesion severity in vivo [106]. The group has chosen to administer four therapeutic doses over the 8 weeks experimental period; however, the rationale for weekly injections only in the first 4 weeks was not clear. There is a need to investigate and better define the time point for administration according to the biodistribution and therapeutic effects of these AMs.

\section{Hyaluronic acid-generated particles for drug delivery}

Many research groups have investigated the atheroprotective effect of particles generated by hyaluronan, or hyaluronic acid (HA). Beldman et al. demonstrated via PET imaging that radiolabeled HA-NPs accumulated at the sites of atherosclerosis in $\mathrm{ApoE}^{-1-}$ mice and resulted in reduced macrophages in the plaque lesions [111]. Interestingly, the authors showed that the uptake of HA-NPs by macrophages was sixfold more effective in early lesions than in advanced plaques [111]. This finding may be due to higher endothelial permeability remodeling in early lesions as compared to advanced plaques, where there are increased collagen and SMC proliferation [112]. Using HA-coated nanocomplexes decorated with lectin-like oxidized low-density lipoprotein receptor (LOX-1) siRNA cell-penetrating peptides, Zhao et al. demonstrated reductions in plaque area by $28 \%$ and neutral lipid content by $37 \%$, as well as less infiltration of macrophages and chemokines in $\mathrm{ApoE}^{-1-}$ mice [113]. Mu et al. loaded simvastatin into biodegradable HA-coated polymeric micelles and found that treatment with these particles resulted in significantly reduced plaque size in $\mathrm{ApoE}^{-/-}$mice on HFD [114]. In these studies, HA may have also played an anti-oxidative role further improving the observed therapeutic effects.

\section{Perfluorocarbon NPs for gene delivery}

Pan et al. created $\mathrm{pH}$-sensing cationic perfluorocarbon NPs and coated them with siRNA against the Jun N-terminal kinase (JNK), a stress-activated protein kinase that mediates proapoptotic responses following stimulation by environmental stresses, cytokines, and growth factors. The authors demonstrated that these particles reduced necrosis and depleted plaque macrophage content in the plaques of $\mathrm{ApoE}^{-/-}$mice after seven doses of treatment [115]. The group also showed a reduction in the time to occlusion in acute thrombosis in the treated mice and attributed this to the NPs' ability to restore the integrity of the endothelial barrier [115]. The choice of perfluorocarbon is interesting because it was previously used as blood substitute and may thus allow a smooth transition into their clinical use. These perfluorocarbon NPs are currently used as 19-Fluorine MRI contrast [116, 117] and ultrasound contrast agents [118], therefore moving forward, these could potentially be used in theranostic approaches.

\section{Peroxisome proliferator-activated receptor gamma agonist}

The peroxisome proliferator-activated receptor gamma (PPAR $\gamma$ ) is a member of the ligand-inducible transcription factor family that regulates glucose homeostasis and is highly expressed in macrophage foam cells [119]. Using two distinct PPAR $\gamma$ agonists, rosiglitazone and GW7845, both of which are insulin sensitizers for the treatment of diabetes, Li et al. successfully limited the development of atherosclerosis in $\mathrm{LDLR}^{-/-}$mice [119]. In this study, these agonists upregulated CD36, but the treated mice also had improved insulin sensitivity and reduced inflammatory markers [119]. This is likely because PPARY is involved in the regulation of various immunological events, including the differentiation and activation of immune cells, and the regulation of cytokine expression, all of which contribute to remodeling of the immune balance [120]. To overcome the high systemic dose required and offtarget effects of such agonists, Giacalone et al. encapsulated rosiglitazone into polymeric NPs and demonstrated that they inhibited inflammatory cytokine (IL-10) expression in RAW264.7 macrophages [121]. This study revealed the potential of PLA-PEG-RSG NPs to suppress the inflammatory response of atherosclerosis. However, more research is needed to enhance these NPs' targeting capacity and test their efficacy in vivo.

\section{Efferocytosis}

Effective efferocytosis and removal of apoptotic cells reduce plaque cellularity and suppress the growth of plaques, whereas ineffective efferocytosis results in the accumulation of apoptotic debris and formation of a 
necrotic core [122-124]. An interesting approach to avoiding the inflammatory repercussions associated with the accumulation of apoptotic cells is to block cellsurface expression of anti-phagocytic signals like CD47. Kojima et al. demonstrated that therapy using an inhibitory antibody directed against CD47 which can increase the effectiveness of efferocytosis was critical for reversing the buildup of foam cells and reduced plaques in vivo [125]. Although the anti-CD47 antibody can offer a new way to increase efferocytosis, this treatment has to be used with caution because the antibody may result in side effects such as erythrophagocytosis and anemia [126].

\section{Lipid metabolism}

Elevated LDL levels in familial hypercholesterolemia are linked to three single genetic mutations: LDL receptors, proprotein convertase subtilisin/kexin type 9 (PCSK9), and apolipoprotein (Apo) B [127].

\section{Promoting lipid storage in liver}

PCSK9, a member of the proteinase K subfamily of subtilases, is a ligand of LDL receptors, causing their degradation in the lysosome [127]. The absence of PCSK9 has been associated with increased expression of LDL receptors, a phenomenon that can be altered with the enhancement of PCSK9 via mRNA gene therapy [128]. In a phase 1 trial, Fizgerald et al. demonstrated that the encapsulation of siRNA against PCSK9 via a lipid NP resulted in a $70 \%$ reduction in circulating PCSK 9 and $40 \%$ reduction in LDL in patients as compared with the placebo group [129]. The downregulation of PCSK9 resulted in higher expression of LDL receptors and more efficient cholesterol absorption, thereby lowering plasma cholesterol levels, and was an effective therapy. A limitation for this approach is the need for multiple injections, hence an increase in cost and health care burden.

Since the minimal promoter region of the PCSK9 gene houses a sterol-regulatory element (SRE), the transcription of PCSK9 is dependent on SRE-binding proteins
(SREBPs). The silencing of these proteins interferes with the PCSK9-LDL receptor pathway, as well as cholesterol biosynthetic activity in the liver, which may help to manage plasma cholesterol levels more effectively. Since NPs passively accumulate in the liver, many research groups have harnessed this property to achieve or enhance their therapeutic strategy for lipid metabolism (Table 3) [130]. SREBPs regulate lipid homeostasis by modulating the genes which control lipid biosynthesis via altering the expression of LDL receptors and the PCSK9 gene. The inhibition of the SREBP cleavage-activating protein (SCAP) resulted in the reduction of circulating PCSK9, LDL, and triglycerides. In a rhesus monkey model, spontaneous dysmetabolic gene therapy, using siRNA against SCAP and lipid-based NPs, decreased PCSK9, LDL, and triglycerides [131, 132]. Similar results were observed via targeting simvastatin with a monoclonal antibody with high affinity to PCSK9 with simvastatin in both mice and rhesus monkeys [10]. In another gene-therapy approach, nanoliposomes with siRNA against ApoB successfully lowered plasma cholesterol levels and expression of LDL receptors in hepatic cells in vivo [133].

\section{Preventing lipid oxidation}

Another compound used as an anti-atherosclerotic agent is selenium, because it has been shown to prevent oxidative modification of lipids, suppress platelet aggregation, and reduce inflammation [134]. However, elevated doses of selenium result in toxicity; therefore, encapsulating selenite into NPs (SeNPs) can significantly lower the toxicity, making them promising for clinical application $[135,136]$. Several studies have investigated the anti-atherosclerotic activities of SeNPs in $\mathrm{ApoE}^{-1-}$ mice on HFD and demonstrated their successful inhibition of hyperlipidemia and reduced inflammation of blood vessels, as well as strong antioxidant capacity $[135,137]$.Overall, the use of monoclonal antibodies, gene therapy and drug loaded NPs have proven to be successful in the reduction of LDL receptor expression and consequently plasma cholesterol

Table 3 NPs targeting lipid metabolism

\begin{tabular}{|c|c|c|c|c|}
\hline Targeting approach & Delivered drugs & Models & Effect & Refs. \\
\hline Lipid NPs & PCSK9 SiRNA & Phase 1 trial (humans) & $\begin{array}{l}\text { Triggered a mean } 70 \% \text { reduction in circulating PCSK9 } \\
\text { and } 40 \% \text { reduction in LDLC in patients compared with } \\
\text { placebo group }\end{array}$ & [129] \\
\hline Lipid NPs & SCAP SIRNA & Dysmetabolic model (Rhesus monkey) & Reduced circulating LDLC, PCSK9, and TG & {$[131,132]$} \\
\hline $\begin{array}{l}\text { Anti-PCSK9 mono- } \\
\text { clonal antibody } \\
\text { (1B20) }\end{array}$ & 1B20/simvastatin & $\operatorname{LDLR}^{ \pm}$mice and Rhesus monkeys & Significant reduced plasma LDLC & [10] \\
\hline Lipid NPs & ApoB siRNA & $\mathrm{LDLR}^{+/-} \mathrm{CETP}^{+/-}$mice model on HFD & $\begin{array}{l}\text { Downregulated expression of ApoB and thus reduced } \\
\text { serum lipid levels }\end{array}$ & [133] \\
\hline SeNPs & Selenium & $\mathrm{ApoE}^{-/-}$mice on HFD & Decreased serum TC and TG levels & {$[135,137]$} \\
\hline
\end{tabular}


levels, however, their direct effects on the progression of atherothrombosis has yet to be determined.

\section{Regulating cholesterol metabolism in macrophages}

By incorporating an agonist to cholesterol-trafficking nuclear liver-X receptors, and thereby regulating cholesterol efflux, Iverson et al. demonstrated less macrophage retention and less cholesterol accumulation in the intimal levels of injured carotid arteries in Sprague-Dawley rats on a high-fat diet (HFD) [105]. Based on the hypothesis that regression of an atherosclerotic plaque can be achieved via reducing the uptake of LDL by macrophages and via stimulating cholesterol efflux, He et al. generated mannose-functionalized dendrimer NPs to deliver the liver-X-receptor ligand and the siRNA against scavenger receptor-A to lesions [138]. This approach inhibited the influx of cholesterol and promoted the efflux of cholesterol, resulting in $20 \%$ regression of atherosclerotic lesions in vivo, offering a novel strategy to halt plaque progression by reversing the generation of foam cells [138].

\section{Smooth muscle cells}

Under normal conditions, vascular SMCs with low-rates of proliferation and apoptosis are responsible for sustaining vessel tone, providing structural support, and regulating vessel homeostasis and development. However, during atherosclerosis, vascular SMCs can also acquire the properties of macrophages and contribute to the formation of foam cells $[21,37]$. Therefore, another approach to controlling the progression of atherosclerosis is through inhibition of SMC proliferation and limiting their uptake of oxLDL. To do this, some groups have looked at using anti-cancer drugs because they possess an anti-proliferative function; however, some of these drugs may induce neutropenia and lymphopenia. The encapsulation of these drugs into NPs has been shown to provide effective therapy while avoiding side effects. Meneghini et al. loaded Docetaxel, is an anti-microtubule agent used to inhibit cell proliferation, into cholesterolrich nanoemulsions; and demonstrated an $80 \%$ reduction in the atherosclerosis lesion area in the aorta of rabbits on HFD post-therapy [139]. These cholesterol-rich nanoemulsions mimic LDL and enter the cells via LDLreceptor-mediated endocytosis [140]. The rabbit model also showed that this therapy resulted in decreased macrophages and vascular SMCs in the lesions [139].

The use of SMCs to inhibit atherosclerotic progression may require more in-depth studies to be performed because of their involvement in diffused intima thickening in human plaques, a trait that is absent in most animal models [141]. In addition, contradictory results have been observed in preclinical models and clinical trials, where an IL-1 $\beta$-neutralizing antibody resulted in the rupture of fibroatheromas in murine models [142] while the clinical trial CANTOS showed beneficial results in reducing CVD events [143]. Therefore, there may be a need to have a better understanding of SMCs, in particular to investigate species differences, so that research groups can develop better therapeutics with better prospects of clinical translation.

\section{Thrombosis}

Most acute clinical events are caused by thrombosis over an underlying disrupted plaque [43]. Thrombosis can evoke numerous serious events such as acute coronary syndromes, ischemic stroke, and pulmonary embolism [144]. The pharmacological therapy for these events uses thrombolytic drugs, which activate plasminogen, dissolve fibrin, and break down blood clots [145]. Furthermore, anti-platelet and anti-coagulant drugs are used to prevent or minimize thrombotic events. Anti-platelet drugs work by preventing platelet activation, adhesion, and aggregation. Anti-coagulants diminish thrombin's activity and hinder the activation of a coagulation cascade. However, most of these drugs need to be intravenously injected at high doses, have short half-lives in systematic circulation, and lead to crucial side effects such as bleeding. Therefore, by targeting the biomarkers of thrombosis for site-specific delivery, we may be able to provide low systematic doses, allowing for the enrichment of drugs and increased potency at the site of disease. Several research groups have also created a range of NPs, including hollow nanogels, magnetic particles, and liposomes, for better thrombolysis (Table 4) [144].

\section{NPs for thrombolytic drug delivery}

The currently used FDA-approved thrombolytic drug for the treatment of acute ischemic stroke is tissue plasminogen activator (tPA), but its usage is limited due to the short therapeutic time window $(<4.5 \mathrm{~h})$ and risk of hemorrhagic complications [146]. The conversion of plasminogen to plasmin is catalyzed by recombinant tPA, a serine protease. Plasmin promotes thrombolysis by degrading the fibrin network of the thrombus [147]. Hu et al. constructed biocompatible tPA-loaded magnetic NPs that could be guided to a blood clot and their drug release triggered locally by an external magnetic field [148]. These magnetic NPs increased thrombolytic efficiency in vivo and lowered the bleeding risk in a rodent study [148]. The magnetic field assists the NPs in accumulating at the location of the thrombus, as well as in stimulating the drug release at the site, resulting in clot lysis efficiency of $70 \%$ as compared to $30 \%$ with free tPA on its own [148]. P-selectin is an activation-specific biomarker of platelets because it is not expressed by resting 
Table 4 Antibodies and NPs targeting thrombus

\begin{tabular}{|c|c|c|c|c|}
\hline Targeting approach & Delivered drugs & Models & Effect & Refs. \\
\hline $\begin{array}{l}\text { Monoclonal antibody targeting the } \\
\text { enzymatic pocket of FXIla }\end{array}$ & $3 \mathrm{~F} 7$ & $\begin{array}{l}\text { ApoE }{ }^{-/-} \text {on HFD (mice); Tandem ste- } \\
\text { nosis model mimicking vulnerable, } \\
\text { rupture-prone plaque (mice) }\end{array}$ & $\begin{array}{l}\text { Decreased stable atherosclerotic } \\
\text { plaque burden. Achieved plaque } \\
\text { stabilization }\end{array}$ & [176] \\
\hline $\begin{array}{l}\text { Perfluorocarbon NPs coated on } \\
\text { stents }\end{array}$ & Thrombin inhibitor (PPACK) & $\begin{array}{l}\text { In vitro flow model of stent throm- } \\
\text { bosis }\end{array}$ & $\begin{array}{l}\text { Suppressed growth of thrombi in } \\
\text { both static and dynamic models of } \\
\text { stent thrombosis }\end{array}$ & [144] \\
\hline $\mathrm{Fe}_{3} \mathrm{O}_{4}$ nanorods & tPA & Ex-vivo thrombi (rats) & Achieved lysis efficiency of 70\% & [148] \\
\hline Fucoidan-functionalized NPs & tPA & Venous thrombosis (mice) & $\begin{array}{l}\text { Significant reduction in thrombus } \\
\text { density }\end{array}$ & [147] \\
\hline \multirow[t]{5}{*}{ scFv against activated GPIIb/IIla } & SCUPA & $\begin{array}{l}\text { Acute arterial thrombosis in C57BI6 } \\
\text { and } \mathrm{plg}^{-1-} \text { (mice) }\end{array}$ & $\begin{array}{l}\text { Displayed successful thrombolysis of } \\
\text { blood clots }\end{array}$ & [160] \\
\hline & CD39 & Acute arterial thrombosis (mice) & $\begin{array}{l}\text { Inhibited aggregation of platelets } \\
\text { and prevented vessel occlusion }\end{array}$ & [164] \\
\hline & CD39 & Cardiac I/R (mice) & $\begin{array}{l}\text { Preserved cardiac function and } \\
\text { significantly reduced infarct size; less } \\
\text { cardiac deformation observed using } \\
\text { strain analysis }\end{array}$ & [165] \\
\hline & TAP & Cardiac I/R (mice) & $\begin{array}{l}\text { Preserved cardiac function and } \\
\text { significantly reduced infarct size }\end{array}$ & [161] \\
\hline & TAP & $\begin{array}{l}\text { Acute arterial and electrolytic } \\
\text { venous thrombosis (mice) }\end{array}$ & $\begin{array}{l}\text { Reduced thrombolysis post therapy; } \\
\text { prophylaxis resulted in reduced } \\
\text { thrombosis }\end{array}$ & [166] \\
\hline $\mathrm{MB}+$ scFv against activated GPIIb/IIla & scuPA & Acute arterial thrombosis (mice) & $\begin{array}{l}\text { Detected and successful in break- } \\
\text { down of thrombi }\end{array}$ & [162] \\
\hline $\begin{array}{l}\text { Micelles + scFv against activated } \\
\text { GPIlb/llla }\end{array}$ & TM & $\begin{array}{l}\text { Laser-induced thrombosis in cre- } \\
\text { master arterioles (mice) }\end{array}$ & $\begin{array}{l}\text { Reduced platelet deposition and } \\
\text { limited thrombus formation }\end{array}$ & [168] \\
\hline $\begin{array}{l}\text { Mesoporous silica particle-targeted } \\
\text { activated GPIlb/Illa }\end{array}$ & UPA & $\begin{array}{l}\text { In vitro human PRP in static and flow } \\
\text { chambers }\end{array}$ & $\begin{array}{l}\text { High affinity to target activated } \\
\text { platelets, concentration-dependent } \\
\text { thrombolysis }\end{array}$ & [167] \\
\hline scFv against red blood cells & TM & Acute venous thrombosis (mice) & $\begin{array}{l}\text { Reduced platelet and fibrin } \\
\text { deposition at all locations of vascular } \\
\text { damage }\end{array}$ & [169] \\
\hline \multirow[t]{3}{*}{$N P s+R G D$} & Aspirin & Acute thrombosis (rats) & $\begin{array}{l}\text { Decreased thrombotic risk, restored } \\
\text { endothelial barrier integrity, plaque } \\
\text { necrosis, and depleted plaque- } \\
\text { macrophage content }\end{array}$ & [151] \\
\hline & IQCA & Arterial thread thrombosis (mice) & Inhibited thrombosis & [156] \\
\hline & Lumbrokinase & Acute arterial thrombosis (rats) & Reduced weight of thrombus & [152] \\
\hline $\begin{array}{l}\text { Platelet membrane-coated nano- } \\
\text { particle (PNPs) }\end{array}$ & Lumbrokinase & Acute arterial thrombosis (mice) & Reduced thrombus area & [155] \\
\hline
\end{tabular}

platelets in the circulation but is highly expressed upon platelet activation in the thrombus. Using fucoidan, a polysaccharide with a high affinity for P-selectin, Juenet et al. created targeted NPs loaded with tPA and observed a significant reduction in thrombus formation in a murine model of thrombosis [147]. However, P-selectin is also expressed by inflamed endothelial cells; therefore, it is not specific to platelets only. This may result in tPA being directed to endothelial cells and could result in unwanted off-target effects and bleeding problems.

The gold standard anti-thrombotic drug that has been studied in large patient populations and proven to provide a significant reduction in the risk of $\mathrm{MI}$ is aspirin $[149,150]$. However, some patients are nonresponders or have resistance to aspirin where their platelet functions cannot be dampened, thereby impeding their treatment for CVDs [151]. Furthermore, aspirin has also been associated with increased risks of gastrointestinal bleeding and hemorrhagic stroke [149]. To overcome this, Jin et al. generated NPs by conjugating a tetrapeptide, Arg-Gly-Asp-Val (RGDV), with aspirin and demonstrated inhibition of thrombosis in vivo [151]. The effective dose of their site-specific aspirin-targeting NPs was 16,700-fold lower than that of free aspirin [151]. Targeting strategies and NPs encapsulation of aspirin or tPA may allow these drugs 
to overcome drawbacks, such as short retention time, drug resistance and other side effects.

\section{RGD peptides}

The Arg-Gly-Asp (RGD) tripeptide sequence is used in many drug-delivery systems to target the proteins within the extracellular matrix for cancer, as well as platelets for anti-thrombotic treatment. Several groups have attempted to use RGD for GPIIb/IIIa targeting in thrombosis, however it is important to note that RGD binds to both the non-activated and activated conformation of this integrin.

Using a cyclic RGD peptide (c-RGD) with better in vivo stability, Liao et al. created targeted chitosan NPs that were coated with lumbrokinase to dissolve fibrin-rich thrombi in Sprague-Dawley rats [152]. This anti-thrombotic drug stimulate adenylate cyclase, increase cAMP level, thereby limiting the increase in intracellular $\mathrm{Ca}^{2+}$, and suppressing the expression of GPIIb/IIIa and P-selectin [153]. Using the same drug, Wang et al. fused platelet membranes with PLGA to generate a platelet membranecoated nanoparticle (PNP) as a carrier [154, 155]. These PNPs were generated from platelet-rich plasma and their membrane proteins allowed them to target thrombosis without modification [155]. The study demonstrated these drug-loaded PNPs showed significant thrombolytic efficacy at a low dose in vivo, with minimal hemorrhagic complications [155].

Wu et al. conjugated a small molecule, 3S-1,2,3,4tetrathydroisoquinoline-3- carboxylic acid (IQCA), to the RGDV motif to target and inhibit P-selectin and GPIIb/IIIa [156]. This compound was reported to successfully inhibit the activation and aggregation of platelets during thrombosis in murine and rodent models [156]. While the RGD sequence has been used in many studies to target GPIIb/IIIa on platelets, this motif is the principal integrin-binding domain present on fibronectin and vitronectin, as well as being present on collagen, laminins, members of the immunoglobulin superfamily, and plasma proteins [151]. Therefore, Li et al. conjugated cRGD peptides onto PLGA NPs to target the $\alpha_{\mathrm{v}} \beta_{3}$ integrin, which is expressed on endothelium during neovascularization [157]. These dexamethasone-loaded NPs were shown to bind to damaged human umbilical vein endothelial cells (HUVECs) and a therapeutic effect of better cell viability was observed in vitro [157]. Therefore RGD has been utilized in numerous studies for targeted drug delivery across the field of cancer, inflammation and thrombosis. Further in vivo experiments may be needed to assess its efficacy and specificity to investigate crossreactivity and off-target effects. Furthermore, clinically used antiplatelet drugs, such as Tirofiban and Eptifibatide, are mimetics of RGD. They have been shown to bind to highly expressed GPIIb/IIIa receptors on platelets, regardless of their conformation states, which in turn result in fatal bleeding complications [158]. GPIIb/IIa on the surface of platelet is inactive in its default normal state; when platelets are activated, however, the complex changes conformation to a high-affinity state for binding to the plasma protein fibrinogen, which promotes thrombosis. Thus, activated GPIIb/IIa is an ideal therapeutic target for inhibiting thrombosis and preventing atherothrombotic events [158].

\section{Single-chain variable fragments against activated GPIIb/IIIa receptors}

To overcome the above issues regarding off-target effects and bleeding complications, recombinant antibody technologies are employed in medical diagnostic and therapeutic applications. Of these, scFvs are one of the most popular choices because they can be genetically modified and are easily produced using different expression systems [159]. The Peter group has developed an scFv that specifically binds to and blocks the fibrinogen pocket of the activated GPIIb/IIIa receptor [158]. Using a fusion of this $\mathrm{scFv}$ to a single-chain urokinase plasminogen activator (Targ-scuPA) in a mouse model of thrombosis, Wang et al. demonstrated the successful thrombolysis of blood clots in real time on ultrasound imaging in vivo [160]. This scFv and scuPA was also conjugated onto MBs in an in vivo theranostic approach for simultaneous diagnosis and treatment (Fig. 6) [161]. In this study, the authors demonstrated that these dual-functional, targeted theranostic MBs successfully enabled visualization of thrombosis in ultrasound imaging, as well as dissolving the clots and providing direct monitoring of thrombolysis in real time [162]. The use of scuPA, a fibrinolytic drug may be an ideal therapeutic candidate for the breakdown of an established clot and has shown great potential to be used in a theranostic strategy.

Hohmann et al. fused the ectonucleoside triphosphate diphosphohydrolase-1 (CD39) to the activated GPIIb/IIIa-specific scFv (Targ-CD39) and demonstrated anti-platelet and anti-inflammatory effects across several murine models [163-165]. CD39 is responsible for hydrolyzing pro-inflammatory ATP and pro-thrombotic ADP to anti-inflammatory AMP; however, the systemic administration of CD39 contributes to a severe bleeding complication [165]. By using Targ-CD39 to target only the activated platelets at the site of thrombosis, this construct was effective in the inhibition of platelet aggregation in vitro, as well as the prevention of vessel occlusion in two acute thrombosis murine models in the mesenteric and carotid arteries [164]. To achieve efficiency in vivo, the nonTarg-CD39 (active CD39 that was genetically fused to a 


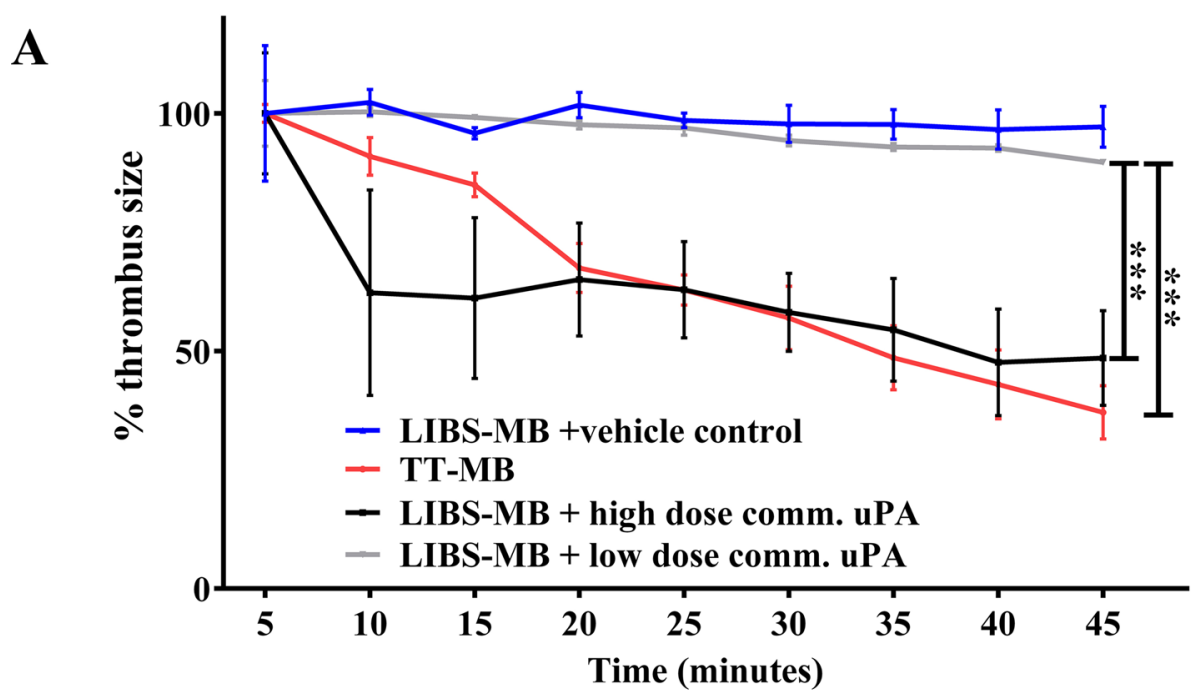

B
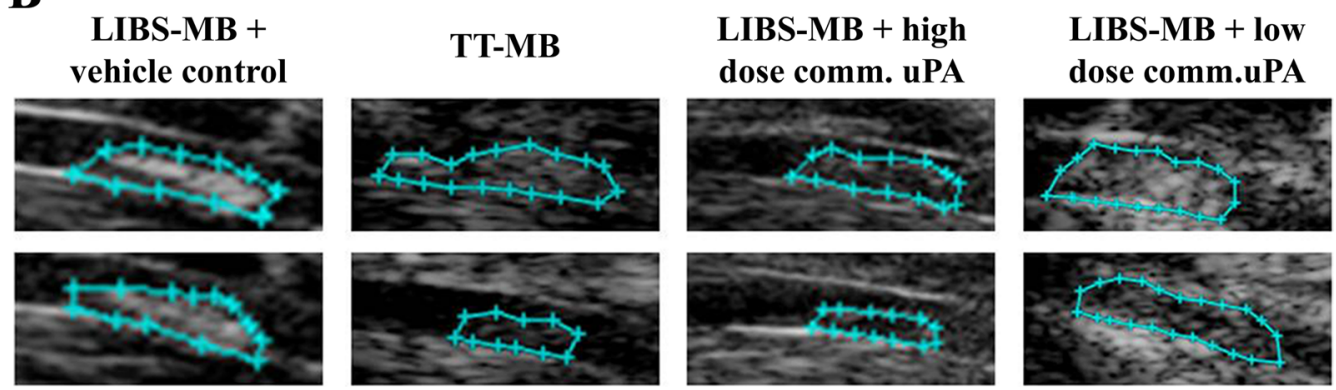

Fig. 6 Proof of thrombus theranostic: Monitoring of thrombolysis via molecular ultrasound imaging showed a reduction of thrombus size post administration of TT-MB. A A reduction of thrombus size was observed for animals administered with LIBS-MB and high dose of commercial uPA at $500 \mathrm{U} / \mathrm{g}$ BW (black line) as compared to LIBS-MB and saline (blue line) as vehicle control. A reduction of thrombus size was also observed with TT-MB (red line) as compared to LIBS-MB and low dose of commercial UPA at $75 \mathrm{U} / \mathrm{g}$ BW (light grey line). B Representative images of baseline versus 45 minutes post-treatment. Baseline area was set to 100\% and areas were calculated every 5 min for 45 min. Thrombus size was traced and calculated using VisualSonics software. Treatment groups were compared by use of repeated measures ANOVA over time with Bonferroni post tests at each time point (Mean $\% \pm$ SEM, $\left(* * p<0.01,{ }^{* * *} p<0.001, n \geq 3\right.$ each) [161]

non-binding scfv as a control) required a dose 10 times higher and resulted in prolonged bleeding [164]. The small dose of Targ-CD39 needed in vivo did not result in systemic overload or prolongation of bleeding time [164]. Ziegler et al. also demonstrated thatTarg-CD39 successfully preserved cardiac function in the treated mice in an MI I/R murine model [165]. In this study, the authors also observed significant cardiac deformation via radial and longitudinal strain and strain rate in vivo, as well as increased inflammatory response in the control animals [165]. The use of soluble CD39 have been previously associated with high rate of bleeding side effect. Fusion of CD39 with GPIIb/IIIa-targeted scFv allowed Targ-CD39 to achieve the delicate balance between fibrinolytic therapy and bleeding side effects. Future in vivo experiments should investigate CD39's dual anti-thrombotic and anti-inflammatory potency for therapy of atherothrombosis.
Another scFv-drug fusion construct from this group uses the tick anti-coagulant peptide (TAP). HanjayaPutra et al. demonstrated that the dual-function antiplatelet/anti-coagulant drug (Targ-TAP) displayed excellent anti-thrombotic capacity across several murine models without significant bleeding influence [166]. Using an MI I/R murine model, Bienvenu et al. showed that Targ-TAP treated mice had preserved heart function on echocardiography and significantly reduced infarct size on histology, as compared to the control group (Fig. 7) [161]. Being a Factor Xa inhibitor, TAP prevents further activation of the coagulation cascade; therefore, it is an ideal candidate for thromboprophylaxis. The employment of Targ-TAP in a prophylactic approach allows up to four hours of protection from thrombosis [166], indicating that further developments of such targeted-drug should also focus on extending their circulating half-life. The ability to provide longer protection will 

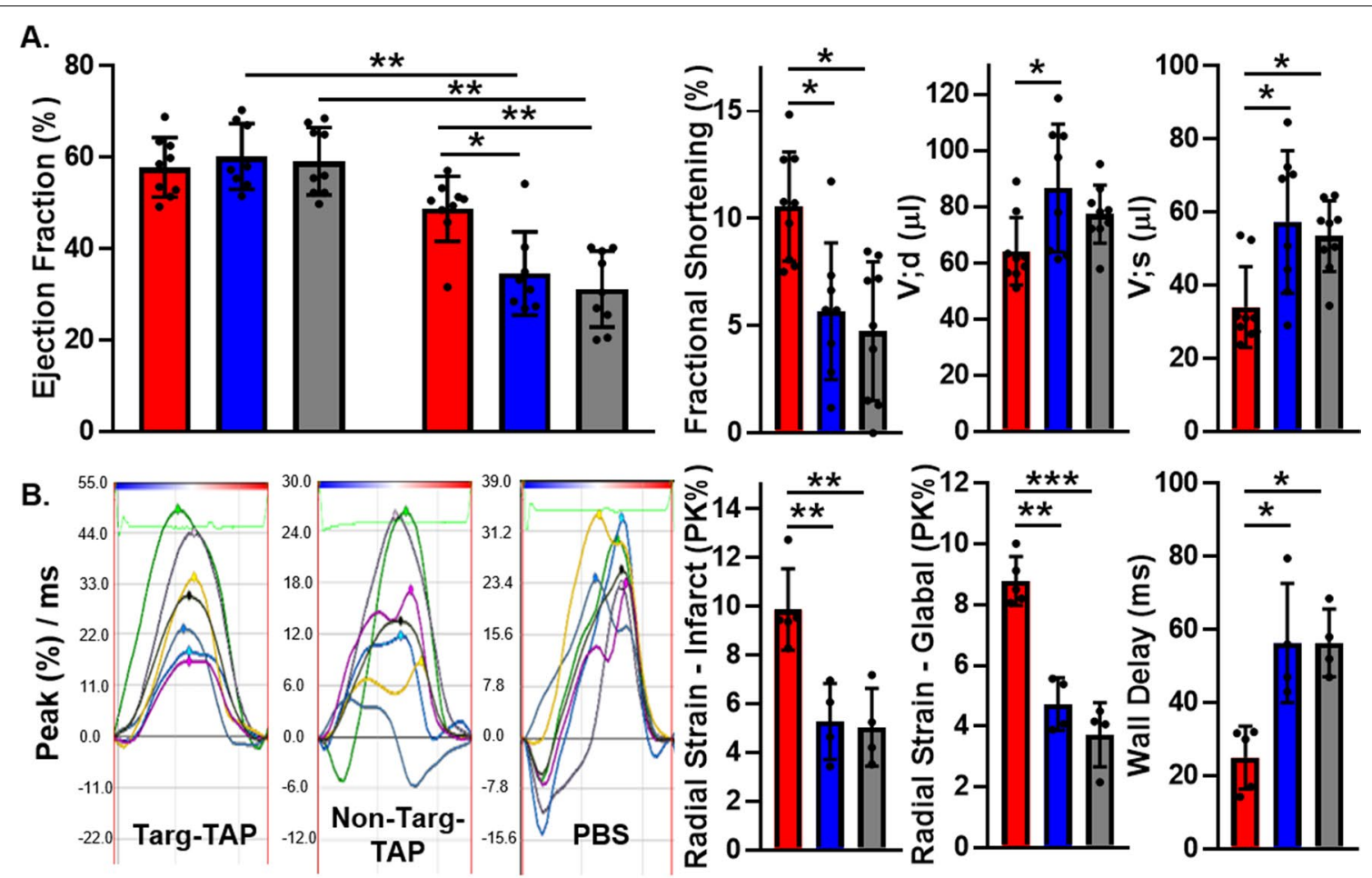

C.
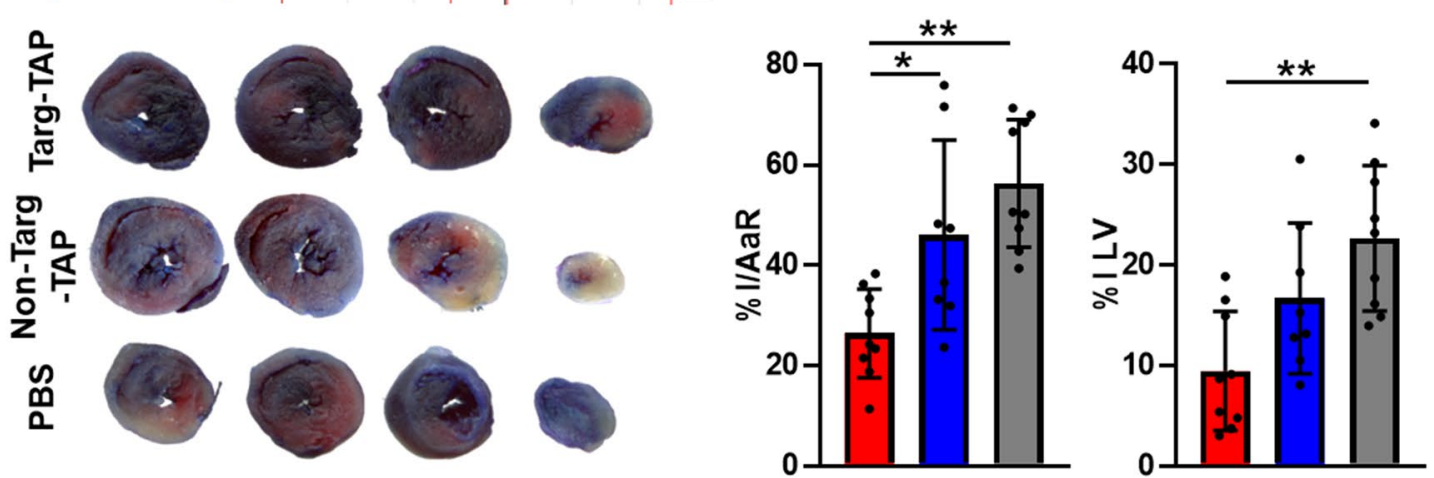

D.

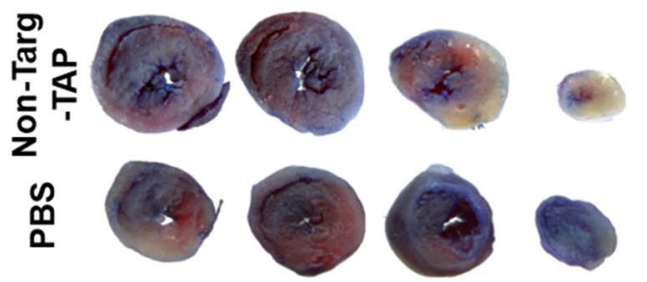

E.
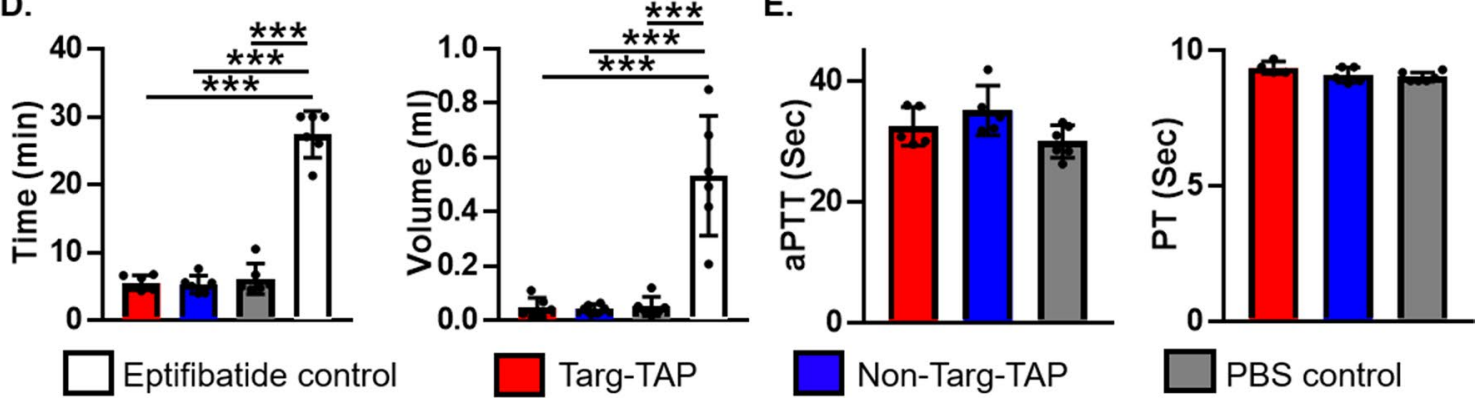

Fig. 7 Targ-TAP preserves myocardial function and reduces infarct size after I/R. A 4-week post-I/R, EF is preserved in Targ-TAP-treated mice as compared to baseline, Non-Targ-TAP or control-treated mice. Targ-TAP also improved FS and prevented V;d and V;s LV dilatation. B Representative radial strain curves. Colored lines represent the six myocardial regions, black lines represent the average (global) strain. Control mice exhibit a marked decrease in radial strain, both in the infarcted area and globally compared to Targ-TAP. Control mice show significant increases in time for maximum opposite-wall delay as compared to Targ-TAP. C Representative images of Evans Blue/TTC stained hearts 4 weeks post-l/R. Targ-TAP-treated hearts show a reduced I/AaR ratio and infarct size compared to controls. D No difference is observed for bleeding time and blood loss in mice injected with Targ-TAP, compared to control; both are significant increased in mice injected with Eptifibatide. E Targ-TAP did not show a difference in aPTT or PT compared to controls. After normality was confirmed (Anderson-Darling and Shapiro-Wilk tests), one-way or two-way ANOVA with Tukey's post-hoc test were applied [161] 
result in less administrations, and therefore cost, which will be an important step for future clinical translation.

In addition to antibody-drug fusion proteins, research groups have conjugated scFvs onto NPs for targeted delivery [167, 168]. Gunawan et al. designed a layered assembly of mesoporous silica conjugated with a thrombin-cleavable sequence and $\mathrm{scFv}$ to generate a multifunctional polymer nanocarrier system for delivery of commercially available urokinase plasminogen activator [167]. These thrombin-cleavable polymer capsules allowed them to control drug release in the microenvironment of the thrombus [167]. The in vitro results showed that the particles had a high affinity to targeting activated platelets and displayed concentration-dependent thrombolysis [167]. Using elastin-based protein polymers, Kim et al. developed targeted multifunctional protein micelles functionalized with both human thrombomodulin fragments and the $\mathrm{scFv}$ specific to activated GPIIb/IIIa receptors [168]. In vivo assays demonstrated that the targeted micelles displayed site-specific binding and significantly reduced platelet deposition and thrombus formation [168]. Zaitsev et al. devised another delivery strategy for thrombomodulin by targeting the membranes of circulating red blood cells and demonstrated significant reductions in platelet and fibrin deposition at the site of vascular damage in vivo [169]. Overall, both direct targeting and NP platforms provided therapeutic effects, however the NP delivery platforms may be more flexible, enabling the incorporation of multiple drugs, which will provide more opportunities towards much needed therapeutic approaches in CVD.

\section{Future directions and limitations}

Targeted therapies and the use of NPs as emerging technologies have attracted major interest in many areas of medicine, including cancers, CVDs, and neurodegenerative disorders. Targeted therapies using peptides, antibodies, and related recombinant proteins have many advantages because of their potential for clinical translation. Most of the current applications require intravenous injection; however, as these strategies develop, there may be formulations that are easier to use subcutaneously or by inhalation.

NPs are used to protect drugs from degradation, carry therapeutic agents to target sites, and facilitate controlled release [48]. In most studies, NPs have been employed in drug delivery for their properties of passive accumulation and phagocytosis by macrophages. The small size of NPs helps them to penetrate capillaries and pass through cell membranes. The flexibility of creating these NPs using a wide range of biomaterials which are biocompatible and biodegradable allows them to be created to provide slow and long-lasting release of drugs. The most established type of particle is nanoliposomes, for several reasons: they are easy to prepare, potential to be modified, have excellent biocompatibility, and have the ability to transport both hydrophilic and lipophilic drugs [170]. Another advantage of nanoliposomes is their ability to enhance gene therapy, in carrying and transferring nucleic acids across the cell membrane. As compared to other genetherapy vectors such as viral vectors, nanoliposomes exhibit high transgenic efficiency without toxicity [83]. In fact, the fast-tracking of these nanoliposomes is evident in the recent approvals of COVID-19 mRNA-based vaccines [51-55]. Nevertheless, these non-targeted NPs have been criticized for their off-target effects and unpredictable side effects. Therefore, some groups have employed ligands to directly target the NPs to specific biomarkers for active targeting, whereas others have used stimuliresponsive NPs that require external stimuli (ultrasound, plasmonic or magnetic responsiveness) for drug delivery $[48,63,162,171,172]$.

Despite all the benefits and the preclinical research conducted in these fields, we must be mindful that there are some limitations to the use of NPs in CVDs. Most NPs are produced in small amounts for preclinical studies and may suffer batch-to-batch variations or face difficulties in upscaling [173]. While some NPs are in clinical use $[51-55,174]$, no more than 20 clinical trials have been registered at ClinicalTrials.gov (search terms "nanoparticle" and "cardiovascular"); therefore, the FDA and European Medicines Agency have yet to approve any cardiovascular nanomedicine products. Effective translation will require the particles to overcome several challenges, including scale-up, drug-loading efficiency, drug-release profile, and stability [175]. The complexity of CVDs requires disease-driven creation of NPs instead of formulation-driven generation. Overall, the applications of cardiovascular nanomedicine for patients are still in their early stages and a considerable amount of effort will be required to achieve clinical breakthrough.

\section{Conclusion}

The cost burden for the management of CVDs is huge. Despite clinical attempts to mitigate risk factors, the progression of atherosclerosis and atherothrombosis is still the cause in one of four deaths. To overcome this, more effective methods are required to improve drug delivery, achieve high therapeutic efficacy, and reduce side effects. Advances in the biotechnology for targeted therapy using peptides and recombinant proteins, as well as nanotechnology for therapeutic-loaded nanomedicine platforms, are attracting major interest. In particular, clinical approvals for cancer therapies and the high-profile clinical approvals of multiple mRNA vaccines for COVID-19 have set the stage for these 
therapies in CVDs. With further advances in targeted therapies and bio-/nano-technologies developed to combat atherosclerosis and atherothrombosis, the clinical translation of these methods will benefit patients across a broad spectrum of CVDs.

\begin{abstract}
Abbreviations
AAA: Abdominal aortic aneurysm; ABC: ATP-binding cassette transporter; ADP: Adenosine diphosphate; AM: Amphiphilic macromolecule; AMP: Adenosine monophosphate; Apo: Apolipoprotein; ATP: Adenosine triphosphate; C6-KH: Lysine- and histidine- oligopeptide-modified pBAE; CCL: Chemokine (C-C motif) ligand; C-RGD: Cyclic RGD peptide; CVD: Cardiovascular disease; CXCL: Chemokine ( $C-X-C$ motif) ligand; DARPin: Designed ankyrin repeat protein; DOPE: Dioleoyl-phosphatidyl-ethanol-amine; F: Factor; FDA: Food and Drug Administration; GP: Glycoprotein; HA: Hyaluronic acid; HAEC: Human aortic endothelial cell; HFD: High-fat diet; HUVEC: Human umbilical vein endothelial cell; ICAM: Intercellular cell adhesion molecule; IL: Interleukin; IQCA: 3S-1,2,3,4-tetrathydroisoquinoline-3-carboxylic acid; JNK: Jun N-terminal kinase; LDL: Low-density lipoprotein; LDLR: Low-density lipoprotein receptor; LOX-1: Lectin-like oxidized low-density lipoprotein receptor; mAb: Monoclonal antibody; Mac-1: aMB2, CD1 1b/CD18, complement receptor 3; MB: Microbubble; MCP-1: Monocyte chemotactic protein-1; MI: Myocardial infarction; miR: MicroRNA; MMP: Matrix metalloprotein; mRNA: MessengerRNA; MSR-1: Scavenger receptor A1; NP: Nanoparticle; OxLDL: Oxidized low-density lipoprotein; PAR: Protease-activated receptor; pBAE: Poly-beta-amino ester; PCSK9: Proprotein convertase subtilisin/kexin type 9; PECAM-1: Platelet endothelial cell adhesion molecule-1; PLGA: Poly(lactic-co-glycolic acid); PNP: Platelet membrane-coated nanoparticle; PPARY: Peroxisome proliferator-activated receptor gamma; rHDL: Reconstituted high-density lipoprotein; RhoA: Ras homolog gene family, member A; ROS: Reactive oxygen species; SARS-CoV-2: Severe acute respiratory syndrome coronavirus 2; SCAP: SREBP cleavageactivating protein; scFv: Single-chain variable fragment; scuPA: Single-chain urokinase plasminogen activator; SeNP: Selenium nanoparticle; sLeX: Sialyl LewisX; SM22a: Smooth muscle protein 22a; SMC: Smooth muscle cell; SR: Scavenger receptor; SRE: Sterol-regulatory element; SREBP: Sterol regulatory element-binding protein; TF: Tissue factor; TNF-a: Tumor necrosis factor-a; tPA: Tissue plasminogen activator; VCAM: Vascular cell adhesion molecule; VWF: von Willebrand factor.
\end{abstract}

\section{Acknowledgements}

Some figures were constructed and used with a granted license from Biorender.

\section{Authors' contributions}

The manuscript was written with contributions of all authors. All authors read and approved the final manuscript.

\section{Funding}

KP is supported by a National Health and Medical Research Council Investigator L3 Fellowship (GNT1174098). XW is supported by a National Heart Foundation Future Leader Fellowship (101932) and a Baker Fellowship.

\section{Availability of data and materials}

Not applicable.

\section{Declarations}

Ethics approval and consent to participate Not applicable.

\section{Consent for publication}

All authors gave their consent for publication.

\section{Competing interests}

The authors declare that they have no competing interests.

\section{Author details}

${ }^{1}$ Molecular Imaging and Theranostics Laboratory, Baker Heart and Diabetes Institute, 75 Commercial Road, Melbourne, VIC 3004, Australia. ${ }^{2}$ Atherothrombosis and Vascular Biology Laboratory, Baker Heart and Diabetes Institute, Melbourne, VIC, Australia. ${ }^{3}$ Burnet Institute, Melbourne, VIC, Australia. ${ }^{4}$ Department of Cardiometabolic Health, University of Melbourne, VIC, Australia. ${ }^{5}$ Department of Medicine, Monash University, Melbourne, VIC, Australia. ${ }^{6} \mathrm{La}$ Trobe Institute for Molecular Science, La Trobe University, Melbourne, VIC, Australia.

Received: 25 August 2021 Accepted: 21 January 2022

Published online: 08 February 2022

\section{References}

1. Kaptoge S, Pennells L, De Bacquer D, Cooney MT, Kavousi M, Stevens $\mathrm{G}$, et al. World Health Organization cardiovascular disease risk charts: revised models to estimate risk in 21 global regions. Lancet Glob Health. 2019;7:e1332-45.

2. Roth GA, Mensah GA, Johnson CO, Addolorato G, Ammirati E, Baddour LM, et al. Global Burden of Cardiovascular Diseases and Risk Factors, 1990-2019. J Am Coll Cardiol. 2020;76:2982-3021.

3. Wang $X$, Peter K. Molecular imaging of atherothrombotic diseases: seeing is believing. Arterioscler Thromb Vasc Biol. 2017;37:1029-40.

4. Banerjee C, Chimowitz MI. Stroke caused by atherosclerosis of the major intracranial arteries. Circ Res. 2017;120:502-23.

5. Zhu Y, Xian X, Wang Z, Bi Y, Chen Q, Han X, et al. Research progress on the relationship between atherosclerosis and inflammation. Biomolecules. 2018:8:80.

6. Lechner K, von Schacky C, McKenzie AL, Worm N, Nixdorff U, Lechner $B$, et al. Lifestyle factors and high-risk atherosclerosis: pathways and mechanisms beyond traditional risk factors. Eur J Prev Cardiol. 2020;27:394-406.

7. Lu W, Yao J, Zhu X, Qi Y. Nanomedicines: redefining traditional medicine. Biomed Pharmacother Biomedecine Pharmacother. 2021;134:111103.

8. McFadyen JD, Schaff M, Peter K. Current and future antiplatelet therapies: emphasis on preserving haemostasis. Nat Rev Cardiol. 2018;15:181-91.

9. Scott AM, Wolchok JD, Old LJ. Antibody therapy of cancer. Nat Rev Cancer. 2012;12:278-87.

10. Zhang L, McCabe T, Condra JH, Ni YG, Peterson LB, Wang W, et al. An anti-PCSK9 antibody reduces LDL-cholesterol on top of a statin and suppresses hepatocyte SREBP-regulated genes. Int J Biol Sci. 2012;8:310-27.

11. Flores AM, Ye J, Jarr K-U, Hosseini-Nassab N, Smith BR, Leeper NJ. Nanoparticle therapy for vascular diseases. Arterioscler Thromb Vasc Biol. 2019;39:635-46.

12. Chenthamara D, Subramaniam S, Ramakrishnan SG, Krishnaswamy S, Essa MM, Lin F-H, et al. Therapeutic efficacy of nanoparticles and routes of administration. Biomater Res. 2019;23:20.

13. Hoshyar N, Gray S, Han H, Bao G. The effect of nanoparticle size on in vivo pharmacokinetics and cellular interaction. Nanomed. 2016;11:673-92.

14. Anselmo AC, Mitragotri S. Cell-mediated delivery of nanoparticles: taking advantage of circulatory cells to target nanoparticles. J Controlled Release. 2014:190:531-41.

15. Wang X, Ziegler M, McFadyen JD, Peter K. Molecular imaging of arterial and venous thrombosis. Br J Pharmacol. 2021;178:4246-69.

16. Badimon L, Padró T, Vilahur G. Atherosclerosis, platelets and thrombosis in acute ischaemic heart disease. Eur Heart J Acute Cardiovasc Care. 2012;1:60-74.

17. Bryan MT, Duckles H, Feng S, Hsiao ST, Kim HR, Serbanovic-Canic J, et al. Mechanoresponsive networks controlling vascular inflammation. Arterioscler Thromb Vasc Biol. 2014;34:2199-205.

18. Cook-Mills JM, Marchese ME, Abdala-Valencia H. Vascular cell adhesion molecule-1 expression and signaling during disease: regulation by reactive oxygen species and antioxidants. Antioxid Redox Signal. 2011;15:1607-38. 
19. Liang S, Zhang J, Ning R, Du Z, Liu J, Batibawa JW, et al. The critical role of endothelial function in fine particulate matter-induced atherosclerosis. Part Fibre Toxicol. 2020;17:61.

20. Ramji DP, Davies TS. Cytokines in atherosclerosis: key players in all stages of disease and promising therapeutic targets. Cytokine Growth Factor Rev. 2015;26:673-85.

21. Bennett MR, Sinha S, Owens GK. Vascular smooth muscle cells in atherosclerosis. Circ Res. 2016;118:692-702.

22. Moore KJ, Sheedy FJ, Fisher EA. Macrophages in atherosclerosis: a dynamic balance. Nat Rev Immunol. 2013;13:709-21.

23. Swirski FK, Pittet MJ, Kircher MF, Aikawa E, Jaffer FA, Libby P, et al. Monocyte accumulation in mouse atherogenesis is progressive and proportional to extent of disease. Proc Natl Acad Sci. 2006;103:10340-5.

24. Cohn J, Kamili A, Wat E, Chung RW, Tandy S. Dietary phospholipids and intestinal cholesterol absorption. Nutrients. 2010;2:116-27.

25. Luo J, Yang H, Song B-L. Mechanisms and regulation of cholesterol homeostasis. Nat Rev Mol Cell Biol. 2020;21:225-45.

26. Kiyosue A, Honarpour N, Kurtz C, Xue A, Wasserman SM, Hirayama A A phase 3 study of evolocumab (AMG 145) in Statin-Treated Japanese patients at high cardiovascular risk. Am J Cardiol. 2016;117:40-7.

27. Sabatine MS, Giugliano RP, Keech AC, Honarpour N, Wiviott SD, Murphy SA, et al. Evolocumab and clinical outcomes in patients with cardiovascular disease. N Engl J Med. 2017;376:1713-22.

28. Walpola PL, Gotlieb Al, Cybulsky MI, Langille BL. Expression of ICAM-1 and VCAM-1 and monocyte adherence in arteries exposed to altered shear stress. Arterioscler Thromb Vasc Biol. 1995;15:2-10.

29. Barrett TJ. Macrophages in atherosclerosis regression. Arterioscler Thromb Vasc Biol. 2020;40:20-33.

30. Leitinger N, Schulman IG. Phenotypic polarization of macrophages in atherosclerosis. Arterioscler Thromb Vasc Biol. 2013;33:1120-6.

31. McLaren JE, Michael DR, Ashlin TG, Ramji DP. Cytokines, macrophage lipid metabolism and foam cells: Implications for cardiovascular disease therapy. Prog Lipid Res. 2011;50:331-47.

32. Flynn MC, Pernes G, Lee MKS, Nagareddy PR, Murphy AJ. Monocytes, macrophages, and metabolic disease in atherosclerosis. Front Pharmacol. 2019;10:666.

33. Moore KJ, Freeman MW. Scavenger receptors in atherosclerosis: beyond lipid uptake. Arterioscler Thromb Vasc Biol. 2006;26:1702-11.

34. Kunjathoor W, Febbraio M, Podrez EA, Moore KJ, Andersson L, Koehn $\mathrm{S}$, et al. Scavenger receptors class $\mathrm{A}-\mathrm{I} / \mathrm{II}$ and $\mathrm{CD} 36$ are the principal receptors responsible for the uptake of modified low density lipoprotein leading to lipid loading in macrophages. J Biol Chem. 2002;277:49982-8.

35. Meyer JM, Ji A, Cai L, van der Westhuyzen DR. High-capacity selective uptake of cholesteryl ester from native LDL during macrophage foam cell formation. J Lipid Res. 2012;53:2081-91.

36. Younis N, Sharma R, Soran H, Charlton-Menys V, Elseweidy M, Durrington PN. Glycation as an atherogenic modification of LDL. Curr Opin Lipidol. 2008;19:378-84.

37. Zhao D, Li J, Xue C, Feng K, Liu L, Zeng P, et al. TL1A inhibits atherosclerosis in apoE-deficient mice by regulating the phenotype of vascular smooth muscle cells. J Biol Chem. 2020;295:16314-27.

38. Chaabane C, Coen M, Bochaton-Piallat M-L. Smooth muscle cell phenotypic switch: implications for foam cell formation. Curr Opin Lipidol. 2014:25:374-9.

39. Pugliese $G$, lacobini $C$, Fantauzzi CB, Menini S. The dark and bright side of atherosclerotic calcification. Atherosclerosis. 2015;238:220-30.

40. Rohwedder I, Montanez E, Beckmann K, Bengtsson E, Dunér P, Nilsson J, et al. Plasma fibronectin deficiency impedes atherosclerosis progression and fibrous cap formation. EMBO Mol Med. 2012;4:564-76.

41. Björnheden T, Levin M, Evaldsson M, Wiklund O. Evidence of hypoxic areas within the arterial wall in vivo. Arterioscler Thromb Vasc Biol. 1999;19:870-6.

42. Doyle B, Caplice N. Plaque neovascularization and antiangiogenic therapy for atherosclerosis. J Am Coll Cardiol. 2007;49:2073-80.

43. Shah PK. Mechanisms of plaque vulnerability and rupture. J Am Coll Cardiol. 2003;41:S15-22

44. Partida RA, Libby P, Crea F, Jang I-K. Plaque erosion: a new in vivo diagnosis and a potential major shift in the management of patients with acute coronary syndromes. Eur Heart J. 2018;39:2070-6.
45. Torii S, Sato Y, Otsuka F, Kolodgie FD, Jinnouchi H, Sakamoto A, et al. Eruptive Calcified Nodules as a Potential Mechanism of Acute Coronary Thrombosis and Sudden Death. J Am Coll Cardiol. 2021;77:1599-611.

46. Moons AHM, Levi M, Peters RJG. Tissue factor and coronary artery diseaseq. Cardiovasc Res. 2002;13:1

47. Pala R, Anju V, Dyavaiah M, Busi S, Nauli SM. Nanoparticle-mediated drug delivery for the treatment of cardiovascular diseases. Int J Nanomedicine. 2020;15:3741-69.

48. Anselmo AC, Mitragotri S. Nanoparticles in the clinic: An update. Bioeng Transl Med. 2019;4:e10143.

49. Stylianopoulos T, Jain RK. Design considerations for nanotherapeutics in oncology. Nanomed Nanotechnol Biol Med. 2015;11:1893-907.

50. Akinc A, Maier MA, Manoharan M, Fitzgerald K, Jayaraman M, Barros $\mathrm{S}$, et al. The Onpattro story and the clinical translation of nanomedicines containing nucleic acid-based drugs. Nat Nanotechnol. 2019;14:1084-7.

51. Baden LR, El Sahly HM, Essink B, Kotloff K, Frey S, Novak R, et al. Efficacy and safety of the mRNA-1273 SARS-CoV-2 vaccine. N Engl J Med. 2021:384:403-16.

52. Corbett KS, Flynn B, Foulds KE, Francica JR, Boyoglu-Barnum S, Werner $A P$, et al. Evaluation of the mRNA-1273 Vaccine against SARS-CoV-2 in nonhuman primates. N Engl J Med. 2020;383:1544-55.

53. Jackson LA, Anderson EJ, Rouphael NG, Roberts PC, Makhene M, Coler $\mathrm{RN}$, et al. An mRNA vaccine against SARS-CoV-2 - preliminary report. N Engl J Med. 2020;383:1920-31.

54. Khurana A, Allawadhi P, Khurana I, Allwadhi S, Weiskirchen R, Banothu $A K$, et al. Role of nanotechnology behind the success of mRNA vaccines for COVID-19. Nano Today. 2021:38:101142.

55. Polack FP, Thomas SJ, Kitchin N, Absalon J, Gurtman A, Lockhart S, et al. Safety and efficacy of the BNT162b2 mRNA Covid-19 vaccine. N Engl J Med. 2020;383:2603-15.

56. Duan H, Zhang Q, Liu J, Li R, Wang D, Peng W, et al. Suppression of apoptosis in vascular endothelial cell, the promising way for natural medicines to treat atherosclerosis. Pharmacol Res. 2021;168:105599.

57. Estrada R, Giridharan G, Prabhu SD, Sethu P. Endothelial cell culture model of carotid artery atherosclerosis. Annu Int Conf IEEE Eng Med Biol Soc. 2011;2011:186-9.

58. Watson MG, Byrne HM, Macaskill C, Myerscough MR. A two-phase model of early fibrous cap formation in atherosclerosis. J Theor Biol. 2018;456:123-36.

59. Manthe RL, Muro S. ICAM-1-targeted nanocarriers attenuate endothelial release of soluble ICAM-1, an inflammatory regulator. Bioeng Trans| Med. 2017;2:109-19.

60. Onat D, Brillon D, Colombo PC, Schmidt AM. Human vascular endothelial cells: a model system for studying vascular inflammation in diabetes and atherosclerosis. Curr Diab Rep. 2011;11:193-202.

61. Park J-G, Ryu SY, Jung I-H, Lee Y-H, Kang KJ, Lee M-R, et al. Evaluation of VCAM-1 antibodies as therapeutic agent for atherosclerosis in apolipoprotein E-deficient mice. Atherosclerosis. 2013;226:356-63.

62. Kheirolomoom A, Kim CW, Seo JW, Kumar S, Son DJ, Gagnon MKJ, et al. Multifunctional nanoparticles facilitate molecular targeting and miRNA delivery to inhibit atherosclerosis in $\mathrm{ApoE}^{-/-}$Mice. ACS Nano. 2015;9:8885-97

63. Wang $X$, Searle AK, Hohmann JD, Liu AL, Abraham M-K, Palasubramaniam J, et al. Dual-targeted theranostic delivery of miRs arrests abdominal aortic aneurysm development. Mol Ther. 2018;26:1056-65.

64. Kumar S, Kim CW, Simmons RD, Jo H. Role of Flow-sensitive microRNAs in endothelial dysfunction and atherosclerosis: mechanosensitive athero-miRs. Arterioscler Thromb Vasc Biol. 2014;34:2206-16.

65. Son DJ, Kumar S, Takabe W, Woo Kim C, Ni C-W, Alberts-Grill N, et al. The atypical mechanosensitive microRNA-712 derived from pre-ribosomal RNA induces endothelial inflammation and atherosclerosis. Nat Commun. 2013:4:3000.

66. Fan D, Kassiri Z. Biology of tissue inhibitor of metalloproteinase 3 (TIMP3), and its therapeutic implications in cardiovascular pathology. Front Physiol. 2020;11:661

67. Johnson JL, George SJ, Newby AC, Jackson CL. Divergent effects of matrix metalloproteinases $3,7,9$, and 12 on atherosclerotic plaque 
stability in mouse brachiocephalic arteries. Proc Natl Acad Sci. 2005;102:15575-80.

68. Shimizu K, Mitchell RN, Libby P. Inflammation and cellular immune responses in abdominal aortic aneurysms. Arterioscler Thromb Vasc Biol. 2006;26:987-94.

69. Golledge J, Muller J, Daugherty A, Norman P. Abdominal aortic aneurysm: pathogenesis and implications for management. Arterioscler Thromb Vasc Biol. 2006;26:2605-13.

70. Schober A, Nazari-Jahantigh M, Wei Y, Bidzhekov K, Gremse F, Grommes $J$, et al. MicroRNA-126-5p promotes endothelial proliferation and limits atherosclerosis by suppressing Dlk1. Nat Med. 2014;20:368-76.

71. Golledge J, Norman P. Atherosclerosis and abdominal aortic aneurysm: cause, response or common risk factors? Arterioscler Thromb Vasc Biol. 2010;30:1075-7.

72. Li X, Xiao H, Lin C, Sun W, WU T, Wang J, et al. Synergistic effects of liposomes encapsulating atorvastatin calcium and curcumin and targeting dysfunctional endothelial cells in reducing atherosclerosis. Int J Nanomedicine. 2019;14:649-65.

73. Tsoref O, Tyomkin D, Amit U, Landa N, Cohen-Rosenboim O, Kain D, et al. E-selectin-targeted copolymer reduces atherosclerotic lesions, adverse cardiac remodeling, and dysfunction. J Controlled Release. 2018;288:136-47.

74. Ma S, Tian XY, Zhang Y, Mu C, Shen H, Bismuth J, et al. E-selectin-targeting delivery of microRNAs by microparticles ameliorates endothelial inflammation and atherosclerosis. Sci Rep. 2016;6:22910.

75. Ye Z, Zhang S, Liu Y, Wang S, Zhang J, Huang R. A Peptide analogue of selectin ligands attenuated atherosclerosis by inhibiting monocyte activation. Mediators Inflamm. 2019;2019:1-15.

76. Ueyama T, Ikeda H, Haramaki N, Kuwano K, Imaizumi T. Effects of monoclonal antibody to $\mathrm{p}$-selectin and analogue of Sialyl lewis X on cyclic flow variations in stenosed and endothelium-injured canine coronary arteries. Circulation. 1997;95:1554-9.

77. Ikeda H, Ueyama T, Murohara T, Yasukawa H, Haramaki N, Eguchi H, et al. Adhesive interaction between P-selectin and sialyl Lewis $(\mathrm{x})$ plays an important role in recurrent coronary arterial thrombosis in dogs. Arterioscler Thromb Vasc Biol. 1999;19:1083-90.

78. Jin K, Luo Z, Zhang B, Pang Z. Biomimetic nanoparticles for inflammation targeting. Acta Pharm Sin B. 2018:8:23-33.

79. Simion V, Constantinescu CA, Stan D, Deleanu M, Tucureanu MM, Butoi E, et al. P-selectin targeted dexamethasone-loaded lipid nanoemulsions: a novel therapy to reduce vascular inflammation. Mediators Inflamm. 2016:2016:1-15.

80. Mocanu CA, Fuior EV, Voicu G, Rebleanu D, Safciuc F, Deleanu M, et al. P-selectin targeted RAGE-shRNA lipoplexes alleviate atherosclerosisassociated inflammation. J Controlled Release. 2021;338:754-72.

81. Kona S, Dong J-F, Liu Y, Tan J, Nguyen KT. Biodegradable nanoparticles mimicking platelet binding as a targeted and controlled drug delivery system. Int J Pharm. 2012;423:516-24.

82. Wadhwa A, Aljabbari A, Lokras A, Foged C, Thakur A. Opportunities and challenges in the delivery of mRNA-based vaccines. Pharmaceutics. 2020;12:102.

83. Michel T, Luft D, Abraham M-K, Reinhardt S, Salinas Medina ML, Kurz J, et al. Cationic nanoliposomes Meet mRNA: efficient delivery of modified mRNA using hemocompatible and stable vectors for therapeutic applications. Mol Ther - Nucleic Acids. 2017;8:459-68.

84. Abraham M-K, Peter K, Michel T, Wendel HP, Krajewski S, Wang X. Nanoliposomes for safe and efficient therapeutic mRNA delivery: a step toward nanotheranostics in inflammatory and cardiovascular diseases as well as cancer. Nanotheranostics. 2017;1:154-65.

85. Kanthi YM, Sutton NR, Pinsky DJ. CD39: interface between vascular thrombosis and inflammation. Curr Atheroscler Rep. 2014;16:425.

86. Dwyer KM, Robson SC, Nandurkar HH, Campbell DJ, Gock H, MurraySegal $\amalg$, et al. Thromboregulatory manifestations in human CD39 transgenic mice and the implications for thrombotic disease and transplantation. J Clin Invest. 2004;1 13:1440-6.

87. Dosta P, Demos C, Ramos V, Kang DW, Kumar S, Jo H, et al. Delivery of siRNA to endothelial cells in vivo using lysine/histidine oligopeptidemodified poly( $\beta$-amino ester) nanoparticles. Cardiovasc Eng Technol. 2021;12:114-25
88. Perni S, Preedy EC, Prokopovich P. Amplify antimicrobial photo dynamic therapy efficacy with poly-beta-amino esters (PBAEs). Sci Rep. 2021:11:7275.

89. Mitroulis I, Alexaki VI, Kourtzelis I, Ziogas A, Hajishengallis G, Chavakis T. Leukocyte integrins: Role in leukocyte recruitment and as therapeutic targets in inflammatory disease. Pharmacol Ther. 2015;147:123-35

90. Podolnikova NP, Kushchayeva YS, Wu Y, Faust J, Ugarova TP. The Role of Integrins aMß2 (Mac-1, CD11b/CD18) and aDß2 (CD11d/CD18) in Macrophage Fusion. Am J Pathol. 2016;186:2105-16.

91. Peter K, Schwarz M, Conradt C, Nordt T, Moser M, Kübler W, et al, Heparin inhibits ligand binding to the leukocyte integrin Mac-1 (CD11b/CD18). Circulation. 1999;100:1533-9.

92. Siegel PM, Bojti I, Bassler N, Holien J, Flierl U, Wang X, et al. A DARPin targeting activated Mac-1 is a novel diagnostic tool and potential anti-inflammatory agent in myocarditis, sepsis and myocardial infarction. Basic Res Cardiol. 2021;116:17.

93. Katsuki S, Matoba T, Nakashiro S, Sato K, Koga J, Nakano K, et al. Nanoparticle-mediated delivery of pitavastatin inhibits atherosclerotic plaque destabilization/rupture in mice by regulating the recruitment of inflammatory monocytes. Circulation. 2014;129:896-906.

94. Wang Y, Li L, Zhao W, Dou Y, An H, Tao H, et al. Targeted therapy of atherosclerosis by a broad-spectrum reactive oxygen species scavenging nanoparticle with intrinsic anti-inflammatory activity. ACS Nano. 2018;12:8943-60.

95. Li L, Guo J, Wang Y, Xiong X, Tao H, Li J, et al. A Broad-Spectrum ROS-eliminating material for prevention of inflammation and drug-induced organ toxicity. Adv Sci Weinh Baden-Wurtt Ger. 2018;5:1800781.

96. Duivenvoorden R, Tang J, Cormode DP, Mieszawska AJ, Izquierdo-Garcia D, Ozcan C, et al. A statin-loaded reconstituted high-density lipoprotein nanoparticle inhibits atherosclerotic plaque inflammation. Nat Commun. 2014:5:3065.

97. Choudhury RP, Rong JX, Trogan E, Elmalem VI, Dansky HM, Breslow JL, et al. High-density lipoproteins retard the progression of atherosclerosis and favorably remodel lesions without suppressing indices of inflammation or oxidation. Arterioscler Thromb Vasc Biol. 2004;24:1904-9.

98. Pászty C, Maeda N, Verstuyft J, Rubin EM. Apolipoprotein Al transgene corrects apolipoprotein E deficiency-induced atherosclerosis in mice. J Clin Invest. 1994:94:899-903.

99. Rubin EM, Krauss RM, Spangler EA, Verstuyft JG, Clift SM. Inhibition of early atherogenesis in transgenic mice by human apolipoprotein Al. Nature. 1991;353:265-7.

100. Sanchez-Gaytan BL, Fay F, Lobatto ME, Tang J, Ouimet M, Kim Y, et al. HDL-Mimetic PLGA nanoparticle to target atherosclerosis plaque macrophages. Bioconjug Chem. 2015;26:443-51.

101. Groner J, Goepferich A, Breunig M. Atherosclerosis: Conventional intake of cardiovascular drugs versus delivery using nanotechnology - a new chance for causative therapy? J Controlled Release. 2021;333:536-59.

102. CSL Behring. A Phase 3, Multicenter, Double-blind, Randomized, Placebo-controlled, Parallel-group Study to Investigate the Efficacy and Safety of CSL112 in Subjects With Acute Coronary Syndrome [Internet]. clinicaltrials.gov; 2021 Nov. Report No.: NCT03473223. https://clinicaltr ials.gov/ct2/show/NCT03473223

103. Chmielowski RA, Abdelhamid DS, Faig JJ, Petersen LK, Gardner CR, Uhrich KE, et al. Athero-inflammatory nanotherapeutics: Ferulic acid-based poly(anhydride-ester) nanoparticles attenuate foam cell formation by regulating macrophage lipogenesis and reactive oxygen species generation. Acta Biomater. 2017;57:85-94.

104. Chnari E, Nikitczuk JS, Wang J, Uhrich KE, Moghe PV. Engineered polymeric nanoparticles for receptor-targeted blockage of oxidized low density lipoprotein uptake and atherogenesis in macrophages. Biomacromol. 2006;7:1796-805.

105. Iverson NM, Plourde NM, Sparks SM, Wang J, Patel EN, Shah PS, et al. Dual use of amphiphilic macromolecules as cholesterol efflux triggers and inhibitors of macrophage athero-inflammation. Biomaterials. 2011;32:8319-27. 
106. Lewis DR, Petersen LK, York AW, Zablocki KR, Joseph LB, Kholodovych $V$, et al. Sugar-based amphiphilic nanoparticles arrest atherosclerosis in vivo. Proc Natl Acad Sci. 2015;112:2693-8.

107. Moretti A, Li Q, Chmielowski R, Joseph L, Moghe P, Uhrich K. Nanotherapeutics containing lithocholic acid-based amphiphilic scorpion-like macromolecules reduce in vitro inflammation in macrophages: implications for atherosclerosis. Nanomaterials. 2018:8:84.

108. Chan JW, Lewis DR, Petersen LK, Moghe PV, Uhrich KE. Amphiphilic macromolecule nanoassemblies suppress smooth muscle cell proliferation and platelet adhesion. Biomaterials. 2016;84:219-29.

109. Wallert M, Bauer J, Kluge S, Schmölz L, Chen Y-C, Ziegler M, et al. The vitamin E derivative garcinoic acid from Garcinia kola nut seeds attenuates the inflammatory response. Redox Biol. 2019;24:101166.

110. Hood E, Simone E, Wattamwar P, Dziubla T, Muzykantov V. Nanocarriers for vascular delivery of antioxidants. Nanomed. 2011;6:1257-72.

111. Beldman TJ, Senders ML, Alaarg A, Pérez-Medina C, Tang J, Zhao Y, et al. Hyaluronan nanoparticles selectively target plaque-associated macrophages and improve plaque stability in atherosclerosis. ACS Nano. 2017;11:5785-99.

112. Beldman TJ, Malinova TS, Desclos E, Grootemaat AE, Misiak ALS, van der Velden $\mathrm{S}$, et al. Nanoparticle-aided characterization of arterial endothelial architecture during atherosclerosis progression and metabolic therapy. ACS Nano. 2019;13:13759-74.

113. Zhao Y, He Z, Gao H, Tang H, He J, Guo Q, et al. Fine tuning of core-shell structure of hyaluronic acid/cell-penetrating peptides/sirna nanoparticles for enhanced gene delivery to macrophages in antiatherosclerotic therapy. Biomacromol. 2018;19:2944-56.

114. Mu D, Li J, Qi Y, Sun X, Liu Y, Shen S, et al. Hyaluronic acid-coated polymeric micelles with hydrogen peroxide scavenging to encapsulate statins for alleviating atherosclerosis. J Nanobiotechnology. 2020:18:179.

115. Pan H, Palekar R, Hou K, Bacon J, Yan H, Springer L, et al. Anti-JNK2 peptide\&ndash;siRNA nanostructures improve plaque endothelium and reduce thrombotic risk in atherosclerotic mice. Int J Nanomed. 2018;13:5187-205.

116. Wang X, Temme S, Grapentin C, Palasubramaniam J, Walsh A, Krämer W, et al. Fluorine-19 magnetic resonance imaging of activated platelets. J Am Heart Assoc. 2020;9:e016971.

117. Flögel U, Temme S, Jacoby C, Oerther T, Keul P, Flocke V, et al. Multitargeted 1H/19F MRI unmasks specific danger patterns for emerging cardiovascular disorders. Nat Commun. 2021;12:5847.

118. Walsh APG, Gordon HN, Peter K, Wang X. Ultrasonic particles: An approach for targeted gene delivery. Adv Drug Deliv Rev. 2021:179:113998.

119. Li AC, Brown KK, Silvestre MJ, Willson TM, Palinski W, Glass CK. Peroxisome proliferator-activated receptor $\gamma$ ligands inhibit development of atherosclerosis in LDL receptor-deficient mice. J Clin Invest. 2000;106:523-31.

120. Ricote M, Li AC, Willson TM, Kelly CJ, Glass CK. The peroxisome proliferator-activated receptor gamma is a negative regulator of macrophage activation. Nature. 1998;391:4

121. Giacalone G, Tsapis N, Mousnier L, Chacun H, Fattal E. PLA-PEG nanoparticles improve the anti-inflammatory effect of rosiglitazone on macrophages by enhancing drug uptake compared to free rosiglitazone. Materials. 2018;11:1845.

122. Gonzalez L, Trigatti BL. Macrophage apoptosis and necrotic core development in atherosclerosis: a rapidly advancing field with clinical relevance to imaging and therapy. Can J Cardiol. 2017;33:303-12.

123. Martinet W, Coornaert I, Puylaert P, De Meyer GRY. Macrophage death as a pharmacological target in atherosclerosis. Front Pharmacol. 2019;10:306.

124. Simion V, Zhou H, Haemmig S, Pierce JB, Mendes S, Tesmenitsky Y, et al. A macrophage-specific IncRNA regulates apoptosis and atherosclerosis by tethering HuR in the nucleus. Nat Commun. 2020;11:6135.

125. Kojima Y, Volkmer J-P, McKenna K, Civelek M, Lusis AJ, Miller CL, et al. CD47-blocking antibodies restore phagocytosis and prevent atherosclerosis. Nature. 2016;536:86-90.

126. Wang L, Li H, Tang Y, Yao P. Potential mechanisms and effects of efferocytosis in atherosclerosis. Front Endocrinol. 2021;11:585285.
127. Tavori H, Rashid S, Fazio S. On the function and homeostasis of PCSK9. reciprocal interaction with $L D L R$ and additional lipid effects. Atherosclerosis. 2015:238:264-70.

128. Rashid S, Curtis DE, Garuti R, Anderson NN, Bashmakov Y, Ho YK, et al. Decreased plasma cholesterol and hypersensitivity to statins in mice lacking Pcsk9. Proc Natl Acad Sci. 2005;102:5374-9.

129. Fitzgerald K, Frank-Kamenetsky M, Shulga-Morskaya S, Liebow A, Bettencourt BR, Sutherland JE, et al. Effect of an RNA interference drug on the synthesis of proprotein convertase subtilisin/kexin type 9 (PCSK9) and the concentration of serum LDL cholesterol in healthy volunteers: a randomised, single-blind, placebo-controlled, phase 1 trial. Lancet. 2014;383:60-8.

130. Shi B, Keough E, Matter A, Leander K, Young S, Carlini E, et al. Biodistribution of Small Interfering RNA at the organ and cellular levels after lipid nanoparticle-mediated delivery. J Histochem Cytochem. 2011:59:727-40.

131. Jensen KK, Tadin-Strapps M, Wang S, Hubert J, Kan Y, Ma Y, et al. Dosedependent effects of siRNA-mediated inhibition of SCAP on PCSK9, LDLR, and plasma lipids in mouse and rhesus monkey. J Lipid Res. 2016;57:2150-62.

132. Murphy BA, Tadin-Strapps M, Jensen K, Mogg R, Liaw A, Herath K, et al. siRNA-mediated inhibition of SREBP cleavage-activating protein reduces dyslipidemia in spontaneously dysmetabolic rhesus monkeys. Metabolism. 2017:71:202-12.

133. Tadin-Strapps M, Peterson LB, Cumiskey A-M, Rosa RL, Mendoza VH, Castro-Perez J, et al. siRNA-induced liver ApoB knockdown lowers serum LDL-cholesterol in a mouse model with human-like serum lipids. J Lipid Res. 2011;52:1084-97.

134. Rayman MP. Selenium and human health. The Lancet. 2012;379:1256-68.

135. Xiao S, Mao L, Xiao J, Wu Y, Liu H. Selenium nanoparticles inhibit the formation of atherosclerosis in apolipoprotein E deficient mice by alleviating hyperlipidemia and oxidative stress. Eur J Pharmacol. 2021;902:174120

136. Wadhwani SA, Shedbalkar UU, Singh R, Chopade BA. Biogenic selenium nanoparticles: current status and future prospects. Appl Microbiol Biotechnol. 2016;100:2555-66.

137. Guo L, Xiao J, Liu H, Liu H. Selenium nanoparticles alleviate hyperlipidemia and vascular injury in ApoE-deficient mice by regulating cholesterol metabolism and reducing oxidative stress. Metallomics. 2020;12:204-17.

138. He H, Wang J, Yannieb PJ, Korzunc WJ, Yang H, Ghosh S. Nanoparticlebased "Two-pronged" approach to regress atherosclerosis by simultaneous modulation of cholesterol influx and efflux. 2020;13:1.

139. Meneghini BC, Tavares ER, Guido MC, Tavoni TM, Stefani HA, Kalil-Filho $R$, et al. Lipid core nanoparticles as vehicle for docetaxel reduces atherosclerotic lesion, inflammation, cell death and proliferation in an atherosclerosis rabbit model. Vascul Pharmacol. 2019;9:1.

140. Shakeel F, Alanazi FK, Raish M, Haq N, Radwan AA, Alsarra IA. Pharmacokinetic and in vitro cytotoxic evaluation of cholesterolrich nanoemulsion of cholesteryl-succinyl-5-fluorouracil. J Mol Liq. 2015;211:164-8.

141. Basatemur GL, Jørgensen HF, Clarke MCH, Bennett MR, Mallat Z. Vascular smooth muscle cells in atherosclerosis. Nat Rev Cardiol. 2019;16:727-44.

142. Davies MJ, Richardson PD, Woolf N, Katz DR, Mann J. Risk of thrombosis in human atherosclerotic plaques: role of extracellular lipid, macrophage, and smooth muscle cell content. Heart. 1993;69:377-81.

143. Ridker PM, Everett BM, Thuren T, MacFadyen JG, Chang WH, Ballantyne C, et al. Antiinflammatory Therapy with Canakinumab for Atherosclerotic Disease. N Engl J Med. 2017;377:1119-31.

144. Palekar RU, Vemuri C, Marsh JN, Arif B, Wickline SA. Antithrombin nanoparticles inhibit stent thrombosis in ex vivo static and flow models. J Vasc Surg. 2016;64:1459-67.

145. Zhang L, Li Z, Ye X, Chen Z, Chen Z-S. Mechanisms of thrombosis and research progress on targeted antithrombotic drugs. Drug Discov Today. 2021;\$1359644621002105. 
146. Liu S, Feng X, Jin R, Li G. Tissue plasminogen activator-based nanothrombolysis for ischemic stroke. Expert Opin Drug Deliv. 2018;15:173-84

147. Juenet M, Aid-Launais R, Li B, Berger A, Aerts J, Ollivier V, et al. Thrombolytic therapy based on fucoidan-functionalized polymer nanoparticles targeting P-selectin. Biomaterials. 2018;156:204-16.

148. Hu J, Huang W, Huang S, ZhuGe Q, Jin K, Zhao Y. Magnetically active Fe3O4 nanorods loaded with tissue plasminogen activator for enhanced thrombolysis. Nano Res. 2016:9:2652-61.

149. Halvorsen S, Andreotti F, ten Berg JM, Cattaneo M, Coccheri S, Marchioli $\mathrm{R}$, et al. Aspirin therapy in primary cardiovascular disease prevention. J Am Coll Cardiol. 2014;64:319-27.

150. Schrör K. Aspirin and platelets: the antiplatelet action of aspirin and its role in thrombosis treatment and prophylaxis. Semin Thromb Hemost. 1997;23:349-56

151. Jin S, Wang $Y$, Zhu H, Wang $Y$, Zhao S, Zhao M, et al. Nanosized aspirinArg-Gly-Asp-Val: delivery of aspirin to thrombus by the target carrier Arg-Gly-Asp-Val tetrapeptide. ACS Nano. 2013;7:7664-73.

152. Liao J, Ren X, Yang B, Li H, Zhang Y, Yin Z. Targeted thrombolysis by using C-RGD-modified N, N, N-Trimethyl Chitosan nanoparticles loaded with lumbrokinase. Drug Dev Ind Pharm. 2019;45:88-95.

153. Ji H, Wang L, Bi H, Sun L, Cai B, Wang Y, et al. Mechanisms of lumbrokinase in protection of cerebral ischemia. Eur J Pharmacol. 2008;590:281-9.

154. Hu C-MJ, Fang RH, Wang K-C, Luk BT, Thamphiwatana S, Dehaini D, et al. Nanoparticle biointerfacing by platelet membrane cloaking. Nature. 2015;526:118-21.

155. Wang S, Wang R, Meng N, Guo H, Wu S, Wang X, et al. Platelet membrane-functionalized nanoparticles with improved targeting ability and lower hemorrhagic risk for thrombolysis therapy. J Controlled Release. 2020:328:78-86

156. Wu J, Zhu H, Yang G, He J, Wang Y, Zhao S, et al. Design and synthesis of nanoscaled IQCA-TAVV as a delivery system capable of antiplatelet activation, targeting arterial thrombus and releasing IQCA. Int J Nanomed. 2018;13:1139-58

157. Li Z, Huang H, Huang L, Du L, Sun Y, Duan Y. Prevention of oxidized low density lipoprotein-induced endothelial cell injury by DA-PLGAPEG-CRGD nanoparticles combined with ultrasound. Int J Mol Sci. 2017;18:815.

158. Schwarz M, Meade G, Stoll P, Ylanne J, Bassler N, Chen YC, et al. Conformation-specific blockade of the integrin GPIIb/IIla: a novel antiplatelet strategy that selectively targets activated platelets. Circ Res. 2006;99:25-33.

159. Weisser NE, Hall JC. Applications of single-chain variable fragment antibodies in therapeutics and diagnostics. Biotechnol Adv. 2009;27:502-20

160. Wang X, Palasubramaniam J, Gkanatsas Y, Hohmann JD, Westein E, Kanojia R, et al. Towards effective and safe thrombolysis and thromboprophylaxis: preclinical testing of a novel antibody-targeted recombinant plasminogen activator directed against activated platelets. Circ Res. 2014;114:1083-93.

161. Bienvenu LA, Maluenda A, McFadyen JD, Searle AK, Yu E, Haller C, et al. Combined antiplatelet/anticoagulant drug for cardiac ischemia/reperfusion injury. Circ Res. 2020;127:1211-3.

162. Wang X, Gkanatsas Y, Palasubramaniam J, Hohmann JD, Chen YC, Lim B, et al. Thrombus-targeted theranostic microbubbles: a new technology towards concurrent rapid ultrasound diagnosis and bleeding-free fibrinolytic treatment of thrombosis. Theranostics. 2016;6:726-38.

163. Granja T, Körner A, Glück C, Hohmann JD, Wang X, Köhler D, et al. Targeting CD39 toward activated platelets reduces systemic inflammation and improves survival in sepsis: a preclinical pilot study. Crit Care Med. 2019;47:e420-7.

164. Hohmann JD, Wang $X$, Krajewski S, Selan C, Haller CA, Straub A, et al. Delayed targeting of CD39 to activated platelet GPIIb/IIla via a singlechain antibody: breaking the link between antithrombotic potency and bleeding? Blood. 2013;121:3067-75.

165. Ziegler M, Hohmann JD, Searle AK, Abraham M-K, Nandurkar HH, Wang $X$, et al. A single-chain antibody-CD39 fusion protein targeting activated platelets protects from cardiac ischaemia/reperfusion injury. Eur Heart J. 2018;39:111-6.
166. Hanjaya-Putra D, Haller C, Wang X, Dai E, Lim B, Liu L, et al. Platelet-targeted dual pathway antithrombotic inhibits thrombosis with preserved hemostasis. JCI Insight. 2018;3:e99329.

167. Gunawan ST, Kempe K, Bonnard T, Cui J, Alt K, Law LS, et al. Multifunctional thrombin-activatable polymer capsules for specific targeting to activated platelets. Adv Mater. 2015;27:5153-7.

168. Kim W, Haller C, Dai E, Wang X, Hagemeyer CE, Liu DR, et al. Targeted antithrombotic protein micelles. Angew Chem Int Ed. 2015;54:1461-5.

169. Zaitsev S, Kowalska MA, Neyman M, Carnemolla R, Tliba S, Ding B-S, et al. Targeting recombinant thrombomodulin fusion protein to red blood cells provides multifaceted thromboprophylaxis. Blood. 2012;119:4779-85.

170. Sercombe L, Veerati T, Moheimani F, Wu SY, Sood AK, Hua S. Advances and challenges of liposome assisted drug delivery. Front Pharmacol. 2015;6:286.

171. Refaat A, del Rosal B, Palasubramaniam J, Pietersz G, Wang X, Moulton SE, et al. Near-infrared light-responsive liposomes for protein delivery: towards bleeding-free photothermally-assisted thrombolysis. J Controlled Release. 2021;337:212-23.

172. Refaat A, del Rosal B, Palasubramaniam J, Pietersz G, Wang X, Peter K, et al. Smart delivery of plasminogen activators for efficient thrombolysis; recent trends and future perspectives. Adv Ther. 2021;4:2100047.

173. Cicha I, Chauvierre C, Texier I, Cabella C, Metselaar JM, Szebeni J, et al. From design to the clinic: practical guidelines for translating cardiovascular nanomedicine. Cardiovasc Res. 2018;114:1714-27.

174. Bobo D, Robinson KJ, Islam J, Thurecht KJ, Corrie SR. Nanoparticlebased medicines: a review of FDA-approved materials and clinical trials to date. Pharm Res. 2016;33:2373-87.

175. lafisco M, Alogna A, Miragoli M, Catalucci D. Cardiovascular nanomedicine: the route ahead. Nanomed. 2019;14:2391-4.

176. Searle AK, Chen YC, Wallert M, MCFadyen J, Maluenda A, Noonan J, et al. Pharmacological inhibition of Factor XIla attenuates abdominal aortic aneurysm, reduces atherosclerosis, and stabilizes atherosclerotic plaques. Thromb Haemost. 2021 (in press).

\section{Publisher's Note}

Springer Nature remains neutral with regard to jurisdictional claims in published maps and institutional affiliations.

Ready to submit your research? Choose BMC and benefit from

- fast, convenient online submission

- thorough peer review by experienced researchers in your field

- rapid publication on acceptance

- support for research data, including large and complex data types

- gold Open Access which fosters wider collaboration and increased citations

- maximum visibility for your research: over $100 \mathrm{M}$ website views per year

At BMC, research is always in progress.

Learn more biomedcentral.com/submissions 